\title{
ON THE SYMPTOMATOLOGY
}

\section{TOTAL TRANSVERSE LESIONS OF THE SPINAL CORD;}

WITH SPECIAL REFERENCE TO THE CONDITION OF THE VARIOUS REFLEXES.

BY

H. CHARLTON BASTIAN, M.A., M.D., F.R.S., PROFESSOR OF MRDICINE IN UNIVRRSITY COLLEGE, LONDON; PHYSICIAN TO UNIVRRSITY COLLEG HOSPITAL, AND TO THE NATIONAL HOSPITAL FOR THE PARALYSED AND RPILEPTIC.

Received February 11th-Read February 25th, 1890.

The symptomatology of total transverse lesions affecting the spinal cord either in the cervical or in the upper dorsal region is a subject of great interest both for the physiologist and for the physician. The physiologist, by reason of his observations upon certain of the lower animals, seems to have instilled into the minds of clinical observers the notion that when the spinal cord is absolutely cut off from communication with the encephalon the reflexes dependent upon the spinal cord below the point of section will, in the course of a very short time-that is, as soon as the immediate effects of shock resulting from the operation 
have subsided-exhibit themselves in an exaggerated manner. This general conclusion has perhaps also found favour because of certain other observations upon man himself tending to show that the brain exerts an inhibitory or restraining influence over the reflex activity of the spinal cord. The latter conclusion under ordinary circumstances is undoubtedly quite true, yet it would not be safe to infer that it would also hold good under such very unnatural conditions as must exist when the spinal cord is absolutely cut off from all influences that, under other circumstances, may be exerted upon it by some portions of the cerebrum or of the cerebellum.

As to the observations made by physiologists upon the spinal reflex actions manifested by some animals in whom the spinal cord has been severed from all connection with the brain, I am quite aware that they are at first sight favorable to the notion that in cases of total transverse lesions of the spinal cord occurring in the human subject the reflexes dependent upon the lower portions of the spinal cord would, to say the least, not be diminished. I know quite well that even purposive acts in response to cutaneous stimuli may be manifested by decapitated frogs-acts so complicated and precise as to have given rise to the notion that the spinal cords of these animals must be the seat of a kind of conscious intelligence, capable of accurately adapting response to stimulus. Again, it may be perfectly true that in rabbits and in dogs, in whom the brain has been severed from the spinal cord, reflex actions of a simpler kind are freely elicited, which could only have been produced under the influence of this severed spinal cord. Still, that is not enough to give us a safe warrant for the conclusion that in cases of total transverse lesions in the spinal cord in the human subject the reflexes would, after shock had subsided, become exaggerated. There can be no doubt that the autonomy of the spinal cord diminishes as we ascend in the vertebrate scale. Many of the powers pertaining to it in lower animals are gradually in part taken on by the more developed encephalic centres possessed by 
animals higher in the scale. How complicated are the muscular acts producible by decapitated frogs is now a matter of common knowledge. But experiments which have been made in recent years as to the effects of ablation of the so-called " motor centres" from the cerebral cortex of rabbits, dogs, and monkeys respectively, have also made it abundantly clear that the division between encephalic and spinal functions likewise continues to vary in them very considerably.

Such facts as these are abundantly sufficient to instil into our minds the necessity of exercising great caution before we allow our expectations as to what should occur in man to be guided too exclusively by the results of experiments made upon lower animals. I shall not, therefore, pause to consider what precise amount of warranty has been afforded to us by the experiments of physiologists for the general conclusion which undoubtedly prevails in the minds of medical men, to the effect that in patients suffering from total transverse lesions of the spinal cord the reflexes are, after the effects of shock have subsided, subject to some amount of exaggeration. The question which is of more special importance for us is, what does clinical observation teach us upon the subject?

As long ago as 1882 I expressed a very definite opinion upon this subject, because I had, up to that time, had the opportunity of examining over prolonged periods three typical cases of this kind which had been under my care. In Quain's 'Dictionary of Medicine' I spoke thus concerning the symptomatology of "Complete Transverse Softening involving the mid-dorsal region of the Spinal Cord" (p. 1480) :- "The temperature in the axilla usually varies between $98^{\circ}$ and $100^{\circ} \mathrm{F}$., though with an extension of the pathological process, or towards the close of the disease, it may rise to $101^{\circ}, 102^{\circ}$, or even higher. Meanwhile the lower extremities themselves are often distinctly cold to the hand, the temperature being in some cases more or less subnormal. It is important to note this, because it might have been supposed that hyperæmia and a 
slightly elevated temperature would exist, owing to the vaso-motor nerves of the limbs being paralysed.

"The motor paralysis of the lower extremities is absolute, and the abdominal muscles are also powerless. The feet as the patient lies in bed are extended and often inverted, so that the great toes cross one another. The skin after a time tends to become dry and scurfy. The muscles feel flabby to the hand, but they waste only to a slight extent, and continue week after week to show only a small amount, if any, of diminution in the degree of their irritability to faradic and to galvanic currents.

"The sensibility of the limbs is completely abolished both for tactile and painful impressions, as well as for differences of temperature and tickling. A like abolition of sensibility exists over the trunk up to the level of the ' ensiform area,' whilst above this level the sensibility becomes quite natural. The upper limit of anæsthesia may be quite sharply defined, and in these cases of complete transverse softening there is often no distinct 'girdle sensation.'

"The muscles of the lower extremities may show some slight irritability when they are forcibly tapped, and when the soles of the feet are strongly tickled there may be very slight movements of the toes; but beyond this there is often an entire absence of all reflex movements-there is no ankle-clonus, no knee reflex, and a similar absence of the cremasteric and abdominal reflexes. In the initial stages of the affection, however, and especially when the softening is not completely transverse, all these reflexes may be extremely well marked for a time, though they tend gradually to diminish.

"For the first ten days or a fortnight there is often complete retention of urine, but after this time, when the lumbar region of the cord again becomes capable of manifesting to some extent its centric functions, the initial retention gives place to incontinence of urine. This fluid may be discharged at intervals of two to three hours in small quantities, owing to the occurrence of reflex contrac- 
tions of the bladder whenever it attains a certain degree of fulness. The passage of a catheter, however, in these cases will often show that the bladder is never completely emptied, two to four ounces remaining after the reflex contractions. Unless special precautions are taken the urine in these cases speedily becomes ammoniacal, and more or less loaded with mucus.

"The bowels are usually constipated, and relieved only after the administration of aperients or enemata. At these times there is generally incontinence of fæces, the patients having no power of controlling the reflex actions concerned in defæcation when they have once been strongly excited. The actual passage of the motion is, moreover, often unfelt."

Other authorities in this country, however, as well as abroad, are not in accord with me in regard to the condition of the reflexes in such affections. Thus, limiting the references to the principal recent writers in this country on the subject of diseases of the spinal cord, I will briefly refer to the opinions expressed by Drs. Ross, Bramwell, and Gowers, in relation to the points in question.

In the second edition of his work ' On Diseases of the Nervous System,' published in 1883, Dr. Ross speaks (vol. i, p. 162) of "the general law that diminution of cerebral influence, other things being equal, increases the reflex activity of the cord." Again, whilst referring to the "morbid physiology" of Acute Diffused Myelitis, he says (vol. ii, p. 103) : "When a portion of the grey substance is separated from its connection with the brain by a myelitis situated higher up the cord, reflex actions become increased." A few pages further on he discusses a variety of this disease as "acute transverse myelitis" and concerning it, which is the condition with which we are now more particularly interested, he gives as symptoms for the disease situated in the "dorso-lumbar region" the following (p. 107):- "The paralysed limbs are rigid; the reflexes, both cutaneous and deep, are exaggerated; and there is a tonic spasm of the sphincters. After a time 
the lower extremities become odematous, and their muscles undergo a diffused atrophy; the bladder becomes paralysed, and the urine ammoniacal; acute bedsores appear over the sacrum and trochanters; intermittent fever supervenes, and the patient dies from marasmus." Then he adds, in reference to the disease when it is situated a little higher up in the cord, "In acute dorsal transverse myelitis, however, there is complete absence of bedsores, the bladder is unaffected, and consequently the septicæmia and marasmus are absent." These latter statements are as much at variance with my experience as are the former; it is difficult, indeed, to believe that Dr. Ross can mean these symptoms to refer to the disease where it involves the whole thickness of the cord in either situation; yet he mentions no such limitation, and gives no other account that I have been able to find of the effects of total transverse softening or myelitis.

In the second edition of Dr. Byrom Bramwell's 'Diseases of the Spinal Cord' (1884), in the enumeration of the symptoms of "Total Transverse Lesions," there occurs the following statement (p. 61):-“The reflexes passing through the inferior segments are exaggerated. With the occurrence of secondary degeneration, the paralysed muscles, supplied by inferior segments, become tense and rigid." From what is said on the following page, also, he appears to think that it is the rule to meet with a " band of hyperæsthesia extending round the trunk in the form of a belt," and also with a girdle sensation, so that the "patient feels as if a tight band were drawn round his body."

Dr. Gowers, in his 'Diseases of the Nervous System' (1886), where speaking of "Acute Transverse Myelitis," says (vol. i, p. 225), "The state of reflex action varies, and depends on the position of the disease, in accordance with the laws already stated. An acute lesion in any part of the cord may cause an initial inhibitory loss of reflex action in the part below, but if the lesion is above the lumbar enlargement reflex action returns in the course of 
a few hours. Frequently there is no initial depression. Subsequently the reflex action becomes excessive, that from the skin rapidly, that from the muscles more slowly. Ultimately each attains a high degree of exaltation. . . . The muscles of the limbs are at first flabby and toneless during the stage of initial depression of reflex action, doubtless from the same influence. This condition soon passes off if the lesion is above the lumbar enlargement, and as reflex action becomes active the muscles regain their tone." (See also loc. cit., pp. 136 and 149.)

Elsewhere, when speaking of the determination of the lower level of the lesion in the spinal cord, Dr. Gowers says (loc. cit., p. 156), "To ascertain it we have to examine the functions of the cord as a central organ, and to ascertain how far they are impaired in the paralysed region - to examine especially muscular nutrition and reflex action. The state of muscular nutrition and irritability indicates how far the anterior cornua are injured. The integrity of reflex action indicates the integrity of the reflex loops, and the study of the superficial reflexes of the trunk is especially instructive in this respect." And then he adds, "Excess of superficial reflex action indicates withdrawal of the cerebral controlling influence of the reflex centres, and marked excess of the musclereflexes suggests the existence of a descending degeneration in the lateral columns, since it implies impaired function of the lowest part of the pyramidal tracts."

In my work 'Paralyses : Cerebral, Bulbar, and Spinal,' published a few months earlier, I had already called attention to what I considered the untrustworthy nature of the second test referred to by Dr. Gowers as a means for indicating the lower level of damage in cases of total transverse lesions of the spinal cord. Referring to this subject, I there said (p. 538), "In cases where extensive transverse lesions exist, situated higher in the cord than the nerves upon which any of these reflexes depend, such reflexes are commonly supposed to be exaggerated in intensity. This is, however, far from being always the 
case." After referring to two other possible sources of fallacy in regard to this test I say, "Again, with a total transverse lesion in the lower cervical region, nearly all reflexes dependent upon lower portions of the cord are abolished rather than exaggerated." This being so, it is clear that under certain conditions the "cerebral controlling influence" may be withdrawn with an effect the very reverse of an exaggeration of reflexes; and, on the other hand, it is equally clear, as we shall see, that under similar conditions the most marked descending degenerations may exist in the lateral columns with a complete absence rather than a " marked excess of muscle-reflexes."

I will now give pretty full details concerning four cases of total transverse softening of the spinal cord which have come under my care at University College Hospital during the last eleven years. They are in no sense picked cases. They are, in fact, the only cases in which the lesion has been completely transverse, and where this fact has been verified by an autopsy. In all but one of these cases (No. 3) it was perfectly obvious that the softening through a certain limited part of the lower cervical or of the upper dorsal region of the cord was a total transverse one, seeing that the cord substance thereat was completely diffluent throughout its whole thickness. All the spinal cords were carefully examined after they had been hardened in a solution of bichromate of ammonia. In case No. 3 it was found that both ascending and descending secondary degenerations were just as fully developed as they were in either of the others; and seeing that the symptoms during life were almost precisely similar, it seems safe to conclude that the wider extent though lesser degree of softening which had here existed in the mid-dorsal region had almost sufficed to cut off all encephalic communications with the lower dorsal and lumbar regions of the spinal cord.

Case 1.-Mary F-, at. 38, a nurse, unmarried, was admitted into University College Hospital under my care April 20th, 1881. 
Family history. - Nothing of significance could be ascertained in regard to this.

Past personal history. - The patient had been a governess for twelve years, but six years ago she had to give up this work owing to ill-health. Since this time her occupation has been that of a nurse. She has been very much worried during the last eight years, owing to family troubles. She had always been in good health till six years ago, when she suffered from some nervous complaint, occasioned, as she thinks, by overwork. Under medical treatment she was greatly relieved, and her health continued to improve till May, 1880, when she noticed a lump in her right breast. On account of it she was admitted to this hospital in the following June. She was under Mr. Heath's care, and was treated for "scirrhus of the breast." The breast was removed, and her health greatly improved after the operation. She did not resume her occupation, however, till four months ago. Very soon after this date she began to suffer from great pains in the right shoulder, and soon afterwards in the left shoulder, lasting about half an hour each time : they were very severe at night, and of a lancinating character. The neck and back were subsequently involved in pains of still greater severity; these passed down both arms as far as the elbows : pains were also felt in both thighs, passing from the knees up to the hip-joints. She sought medical advice only three weeks ago, and was soon recommended to come to this hospital.

Present state (April 23rd).- Patient is a rather stout, plethoric woman, lying on her back, and unable to lie on either side on account of pain. She complains of pain in the right breast, in the cervico-dorsal region of the spine, in the shoulders, elbows, and thighs; and of inability to stand or walk. The pains are constant, but paroxysmally worse, and sometimes they are so severe that she shivers.

The skin is everywhere florid; temperature varies from $99^{\circ}$ to $98^{\circ}$. The right mammary gland has been removed, and in its place is a puckered irregular scar about three inches long. The cicatrix is adherent to the chest wall, and the tissues for some distance around are indurated and hard-evidently infiltrated with new growth. Between the scar and the sternum there is a hard nodule in the skin about the size of a bean, and the skin covering it is red. Above the cicatrix there is a similar nodule in the skin; and over the sternum are three other nodules, each about the size of a pea. The tissues in the axilla are somewhat thickened, and there are one or two hard tender glands under the pectoralis muscle. The scar is tender, and is the seat of more or less persistent stabbing pain. The left breast contains one large, rather hard lump about the size of a small orange ; but there is no puckering of skin or retraction of the nipple, and the gland is freely moveable on the pectoral muscle. There is no enlargement of cervical or axillary glands on this side.

Spinal column.-The seventh cervical vertebra is rather prominent. No other unnatural prominence or curvature exists. There is consider- 
able tenderness over the lower cervical and upper dorsal region of the spine; and there is also a great deal of pain referred to the same region.

Nervous system. - No head symptoms or evidence of defective function on the side of any of the cranial nerres.

Sensory apparatus.-There is no loss of tactile sensibility, or inability to appreciate the prick of a pin or to distinguish between heat and cold. She complains of more or less constant burning pains in the elbow-joints, shoulders, and hip-joints, and of a stabbing pain starting in the lower cervical and upper dorsal region of the spine, and passing down through the shoulders to the elbows.

Motor apparatus. - Upper limbs : On the right side she can move her shoulder-, elbow-, and wrist-joints perfectly. She can also flex and extend the fingers. Grasp nil. Movements on left side similar to those on right side. Grasp 10. Lower limbs : Patient is unable to stand or walk. She can raise both legs from the bed, and flex hip-, knee-, and ankle-joints perfectly but not very powerfully. Flexion of toes perfect. She cannot raise herself into the sitting posture without assistance.

Reflexes.-Plantar reflex normal on both sides. Abdominal, epigastric, and gluteal reflexes not obtained. Slight ankle-clonus on both sides. Knee-jerk exaggerated on both sides. She complains of occasional jerkings of the thighs.

Previously to sesterday she had had no difficulty in micturition, but yesterday she had retention of urine for eighteen hours, though the bladder acted after a hot fomentation to the lower part of the abdomen, and she has since passed urine twice. The bowels have not been opened for seven days.

The examination of the thorax and abdomen revealed nothing very unnatural, with the exception that the respirations were 24 per minute, and that the breathing was chiefly abdominal, very little movement of the chest occurring; whilst the pulse was 112 , small, regular, and compressible.

April 26th.-The pain in the cervico-dorsal region of the spine, in the shoulders, and elbows has continued persistently, though paroxysmally worse, since admission. The pain is relieved by morphia gr. $\frac{1}{6}$ administered every four to six hours. She has also been taking six grains of iodide of potassium with an ounce of infusion of calumba three times a day. Diet: Fish or oysters, with ox-tail soup, custard pudding, and wine $\zeta v$.

May 1st.-For the last thirty-four hours she has had retention of urine. A catheter was passed this morning, and $36 \mathrm{oz}$. of acid urine were drawn off. Bowels have never been opened except by an enema, which is administered daily. She can flex the hip-, knee-, and anklejoints and toes very feebly; and she can only just raise the legs from the bed. No anæsthesia. No ankle-clonus exists now on either side. Patellar reflex less marked than on admission. Plantar reflex very slight. 
Temperature at 7 a.m. $97 \cdot 8^{\circ}$; at 11 a.m. $99 \cdot 2^{\circ}$; and at 6 p.m. $98 \cdot 6^{\circ}$. The iodide of potassium has been increased to $15 \mathrm{grrs}$ in infusion of calumba $\jmath_{j}$, three times a day.

3rd.-There is complete motor paralysis of the lower limbs, which has come on since yesterday. Tactile sensibility is also diminished below the knee on both sides. Retention of urine still continues, so that it has to be drawn off three times a day. The pains continue to be of about the same severity. Temperature at 7 a.m. $98 \cdot 2^{\circ}$; at 11 a.m. $99 \cdot 2^{\circ}$; and at 7 p.m. $988^{\circ}$. It has not reached $100^{\circ}$ since admission.

6th.-Motor paralysis still persists in lower limbs. Tactile sensibility now lost below hip-joints. Abdominal, epigastric, gluteal, and scapular reflexes absent on both sides. Plantar reflex now abolished on both sides. Ankle-clonus also absent. Knee-jerks very slight.

8th.- The patient was placed upon a water-bed sesterday. On the lower part of back on each side of coccyx the skin is red, and there are three dark discoloured bullæ to be seen. No pain or tenderness orer the reddened skin. Tactile sensibility lost between the lower dorsal vertebræ and the umbilicus. Motor paralysis of lower extremities continues. Pains as before. Temperature $98 \cdot 2^{\circ}$. Pulse 120, small, feeble, and compressible. Tongue clean. Retention of urine. Bowels opened by enemata, and she is perfectly conscious of the act.

11th. - The redness of skin over sacrum has not increased, and no new bullæ are seen. Old bullæ same as at first appearance. Pulse 120, extremely feeble and weak. During the last two days the pains have passed down the arms to the palms of the hands. She shivers a great deal, and complains of twitchings in her back and legs, but no jerkings of the legs have ever been noticed by the nurse. Legs feel cold. Iodide of potassium mixture omitted, and one containing ether and tinct. of digitalis with effervescing saline to be taken three times a day.

13th.-Motor power : Complete paralysis of lower extremities. Abdominal muscles somewhat flaccid and apparently paralysed. No movements of elevation or expansion of chest; breathing is entirely diaphragmatic. Considerable weakness of upper limbs. Morements of shoulders limited on both sides, and accompanied by severe pain. Flexion of elbows perfect; extension not farther than an angle of $120^{\circ}$. Movements of wrist perfect. Cannot flex the fingers into the palm or grasp the dynamometer.

19th.- Since last note the pain has been less severe, but of the same character as before. The upper limbs are much weaker; she can only move her arms a few inches from her side. Other movements much as before. She lies with her arms close to her side, her elbows bent at a right angle, the wrists semi-pronated, and the phalangeal joints semiflexed. The lower limbs, completely paralysed, are extended and flaccid, and the feet are inverted. There is now complete loss of tactile and painful sensations below the xiphoid cartilage and the ninth interspace. 
All superficial reflexes, including the plantar, are abolished. There is also no ankle-clonus or knee-jerk to be obtained on either side. Complete retention of urine exists. The catheter is passed three times a day. The urine is acid. She has been unable to retain an enema since last note. Her bowels have been opened twice with castor oil, and on each occasion she has been unconscious of the act and has passed the motions into the bed. Pulse 70-80, much less weak than formerly. Temperature $99^{\circ}$; it has only once since admission reached $100^{\circ}$; it mostly ranges between $97 \cdot 5^{\circ}$ and $99 \cdot 5^{\circ}$.

21st.-Since last note patient's temperature has varied from $99^{\circ}$ to $1026^{\circ}$. Pulse 90. Respiration 24. No cough; no expectoration; no dulness in front of chest, and breath-sounds as on admission; no râles. Back not examined. Yesterday the urine began to dribble away about four hours after the catheter was passed. Bowels opened by purgatives; she cannot retain an enema. She is unconscious of the passage of fæces and of urine. There is complete loss of tactile and painful serisations as high as the fifth interspace. No loss of tactile sensibility in upper limbs. Complete paralysis of intercostal muscles below the fifth interspace, and of ahdominal muscles. All the muscles of the lower limbs contract when tapped with a stethoscope. There is also a slight plantar reflex when the soles of the feet are sharply tapped. No abdominal or epigastric reflex. No ankle-clonus and no knee-jerks. She takes very little food.

28th.-The loss of tactile and painful sensibility reaches as high as the fourth interspace. Temp. $99^{\circ}$. From date of last note up to yesterday it has ranged between $100^{\circ}$ and $101.5^{\circ}$. Bladder washed out twice daily with a weak quinine solution.

June 3rd.-There is a considerable amount of dyspnoa this morning. Expiration is short and forcible, and accompanied by bubbling râles in the throat and all over the chest. No retraction of lower part of chest. Pulse very feeble and thready. Ordered a mixture containing ammonia, ether, and digitalis, together with two ounces of brandy in the twentyfour hours.

4th.-Patient is considerably easier this morning. Breathing quieter. Breath-sounds over front high pitched and accompanied by loud bubbling râles. The prick of a pin is not now felt below the level of the third rib. Has required rather more morphia to deaden the burning and other pains from which she suffers. On May 31st her temperature again rose to $101^{\circ}$, and from that time to the present it has ranged between $100^{\circ}$ and $102 \cdot 6^{\circ}$.

12th. - Patient has had considerable difficulty of breathing during the last three days, owing to the amount of mucus which has accumulated in the bronchi. Pains very severe, morphia only controlling them for a very short time, seldom for more than an hour. Temp. $98 \cdot 8^{\circ}$; since June 5 th it has only once risen as high as $100^{\circ}$. 
13th.-Difficulty of breathing increased to-day. She was ordered a hypodermic injection of $\frac{x}{1} \frac{\mathrm{gr}}{\mathrm{O}}$. of apomorphia, and this was administered at 4.55 p.m. Previously to injection the pulse was 92. After fifteen minutes, without any feeling of nausea, the pulse fell to 76 , and became feeble and irregular. An enema of $\xi^{\text {ss }}$ brandy in $\xi^{i j}$ of beef-tea was given. Pulse 72, and then 80 . No sickness at 5.15, so the fauces were touched with the finger, which induced some retching and the expectoration of a little viscid mucus. Some brandy was given by the mouth. Pulse remained at 80 , small and occasionally intermitting. At 5.25 pulse fell to 54 , was very weak and almost thready; at 5.34 to 58 ; at 5.40 to 52 , very thready, with respiration embarrassed, hands cold and clammy; expression of moribund type. Ether $m x$ vi was now injected over chest, and the pulse slowly but progressively recovered. At about 6 o'clock she began to bring up large quantities of frothy mucus (and for an hour or two afterwards she brought up gulps of mucus at intervalsas though from contraction of bronchi; no vomiting). The breathing afterwards improved materially. At 7 p.m. the pulse was good, about 90 , and the patient comfortable.

14th.-Considerably easier to-day. Breathing much better. Pain continues about the same, but is rather more readily controlled by morphia.

17th.-This morning at 3 a.m. patient had a fit of dyspnoa, lasting about fifteen minutes. She became dusky in the face; no coughing; breathing short and shallow. At the commencement of the fit she flexed both arms on to the shoulders, the fingers were also flexed, and the head was bent over on to the left shoulder.

19th.-This morning at 5 a.m. patient had a similar attack of dyspnœa, which commenced in exactly the same manner, and lasted about the same time. But for these attacks the patient has been much more comfortable, and her breathing much easier since the apomorphia. The affection of sensibility over the front of the chest is not appreciably altered; the prick of a pin is still not felt below the level of the third rib. But this afternoon patient complained of a sensation of tingling all over the body and legs. The bedsore has increased, and the tissues around are dark. There is a sore also on one heel to-day.

28th.- Patient was easier during the night. At 7.30 she had an injection of morphia. At 8 a.m., when turned over on to right side to have bedsore dressed, she turned pale, became cyanosed, and died quietly a few minutes later. Ether was administered hypodermically without any effect upon the pulse; and the pupils became widely dilated just before death.

Autopsy (six hours after death).-After removal of the rertebral arches nothing unnatural was seen; but on cutting through the spinal cord just below the bulb and reflecting it, a slight angular curvature was found at the level of the fourth or the fifth cervical vertebra, though 
involving one vertebra only. In this situation no new growth was seen, but immediately above the angle the substance of the vertebra felt decidedly softer than natural when pressed upon by the finger. After removing the dura mater, which presented nothing unnatural, the spinal cord, about two inches from the point of section, and at a site corresponding with the slight projection above mentioned, was found, for a length of three quarters of an inch, to have only about half the width and depth natural to it in this situation. It was here also soft and flaccid, contrasting notably in this respect with the cord substance above and below. Independently of these signs of softening and atrophy there was no abnormal appearance on the anterior surface of the cord, which presented an average amount of vascularity. Its posterior surface showed the same evidence of atrophy at the site above referred to, but no unnatural vascularity above, below, or over the wasted region. On cutting through the cervical segment of the cord above the wasted portion, the grey matter presented a fair amount of vascularity, not in any way excessive. There was a slightly altered tint in the columns of Goll and in portions of the lateral columns, but otherwise nothing unnatural was seen. On cutting through the softened and atrophied portion of the cord, it was here found to be reduced to a semi-fluid pulp. On making sections through the cord for about two inches below this atrophied and softened region there was distinct evidence of central softening involving the grey matter, since when cut across the central portions swell up above the level of the surrounding white columns. Sections through the remaining dorsal and through the lumbar regions of the cord showed no evidence of softening, nor was any other morbid appearance to be recognised except that the grey matter was rather more anæmic than natural.

Heart : Right side of heart thickly covered with fat. Mitral valve slightly thicker and more opaque than natural. Walls of left ventricle slightly paler than natural, and consistence slightly diminished. Left lung: No adhesions ; about three ounces of yellowish serum in the pleura. Upper lobe on section found to be semisolid and odematous. Portions of the upper and middle regions of this lobe as well as the lowest portion of the lower lobe were in a state of more or less well-marked collapse. Nearly a quarter of the tissue in this lung was in such a condition. Right lung: Adhesions extensive. No fluid in pleura. Large portions of the surface of this organ were emphysematous, but on section it presented a healthy appearance throughout. There was no collapse and no new growth. Liver rather smaller than natural and adherent to under surface of diaphragm. In different parts of its substance were found five nodules of white new growth, varying in size from a small bean to a medium-sized chestnut. Otherwise the cut surface of the organ was rather pale, its lobules were indistinctly marked, and its consistence was slightly above par. Spleen of medium size. No appearance of new growth either superficially or within. 
Cut surface very dark, and consistence rather softer than natural. Left kidney extremely congested; cut surface of deep claret colour throughout. Capsule stripped off easily, leaving surface uniformly congested. No new growth. Right kidney presented similar characters ; congestion just as well marked, but on the surface there was one small patch distinctly paler in colour, which was found to extend for a slight distance into the substance of the organ. (It appeared to be a commencing patch of new growth.) Stomach and intestines presented nothing abnormal. Ovaries : Both hard and cartilaginous to the touch; not distinctly larger than natural. On section they were found to be both tough, and showed an excess of fibrous tissue in their interior. Uterus considerably enlarged; cavity not lengthened; walls thickened and very tough. From posterior part of fundus, on left side, a peduncular growth of the size of a small orange projected. It was nodulated and extremely hard, and on section was seen to consist almost wholly of fibrous tissue. On the right side of the body of the uterus, and completely obscuring its outline, there was a very tough, hard encapsuled growth, about the size of a small orange. The capsule was vascular and about one third of an inch in thickness, and on section the tumour presented similar characters to those of the pedunculated growth above referred to. Brain and its membranes showed nothing unnatural. There was no new growth or focal lesion of any kind.

An examination of the spinal cord after it had been hardened in a solution of bichromate of ammonia showed the following lesions :

A total transverse softening with greatly diminished bulk of the cord substance existed for a length of about three quarters of an inch, beginning near the middle of the cervical swelling.

A section just above the cervical swelling shows wellmarked ascending secondary degenerations in the columns of Goll and in the superficial portions of the lateral tracts.

A section one inch below the lower border of the transverse softening shows descending secondary degenerations in both crossed pyramidal tracts, and to a slight extent in the anterior columns. In addition there are two large, definitely circumscribed, opaque white patches (Fig. 1), the larger of which $(a)$ is situated in the central half of the posterior columns, though it does not occupy much of this portion of the column on the right side. The smaller patch (b) is oval, and situated just outside the right posterior 
cornu. In a section half an inch lower down the latter patch no longer exists, and the one in the posterior columns is smaller and confined to their central region.

FIG. 1.

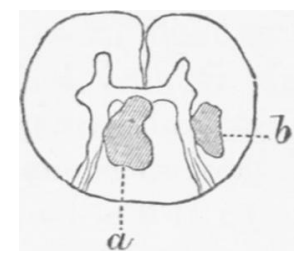

Half an inch lower still a triangular patch exists in the same situation, which has here broken down into a cavity, and is found to extend downwards for about a quarter of an inch.

Farther down-that is, two and a half inches below the lower level of transverse softening-only descending degenerations appear in the posterior parts of the lateral columns, in the "comma-shaped tracts," and (though very slightly marked) in the inner parts of the anterior columns.

One and a half inches lower-that is, about the middorsal region-descending degenerations are seen in similar situations, being still quite well marked in the "commashaped tracts."

In the upper part of the lumbar swelling the descending degenerations are also very well marked in the posterior parts of the lateral columns, and there is a trace of degeneration in the anterior columns, but that of the "comma-shaped tracts" has disappeared.

In the middle of the lumbar swelling the appearances are similar, whilst in the lower third of the lumbar swelling only greatly diminished areas of degeneration in the lateral columns exist.

All through the lumbar swelling, as well as through the lower half of the dorsal region, the grey matter of the cord presents a healthy appearance. 
There is no record of an examination of the cervical vertebræ with the view of ascertaining the nature of the disease which led to the softening and projection of a portion of the body of one vertebra, opposite the softened segment of the cord. Nor was the precise pathogenesis of the latter softening quite clear. The projection certainly was not sufficiently great to have caused much pressure upon the cord, though it may have set up primarily an irritation of the anterior columns. At the time of the autopsy there were no appearances in the cord, or in its membranes contiguous to the softened region, in the least indicative of an inflammatory process; nor, on the other hand, was there any evidence of arterial thrombosis.

The pains from which the patient suffered were very severe in the upper extremities, and, strangely enough, severe pains were felt also in the thighs, as well as burning pains in the hip-joints. These latter severe pains are not easily to be explained. From the note of May 19th it would appear that the arms were then in very much the same position as that described by Dr. Thorburn ('Brain,' October, 1888, p. 293) as resulting from disease high enough to paralyse the deltoids, viz. at or just above the level of the fifth cervical nerve. The patient seemed dying from suffocation at the time of the injection of the apomorphia, and it was only ordered in view of the inevitable consequences if the rapidly accumulating mucus could not be expelled. The danger was undoubtedly great from the remedy, but the subsequent relief was no less striking. Strangely enough, too, the great bulk of the mucus was not expelled by vomiting, but rather by what appeared to be successive contractions of the bronchial tubes. From the note made on May 21 st it will be seen that the limbs were completely flaccid and paralysed, that all the reflexes (superficial and deep) were absent, but that the idio-muscular contractility was present in all the muscles of the lower extremities when they were tapped with a stethoscope; and possibly what is called in the notes a "slight, plantar reflex" was produced in this manner. This idio- 
muscular contraction is now generally considered to be quite distinct from a reflex action. ${ }^{1}$ According to Schiff, Kühne, and others, it is supposed to be due to the proper excitability of the muscular tissue itself. Funke and Weber have been able to produce the phenomenon in the human corpse even twenty-four hours after death, though Onimus could not elicit it later than eight hours after death.

CASE 2.-M. A. W-, rt. 24, a dressmaker, was transferred to my care at University College Hospital on October 14th, 1880, from one of the surgical wards, to which she had been admitted a week previously. She was suffering from recurrent cancer of the left breast with secondary disease of the spine, affecting the spinal cord and causing paraplegia.

The patient's father died of apoplexy, xt. 79, and there is no other history of nervous disease. Her grandmother died of cancer, and her mother, æt. 80, has a tumour of the breast.

Personal history. - The patient is a single woman, there is no specific history, and until a tumour appeared in her breast she never had any illness except "intermittent fever" when seventeen years old. About four years ago she first noticed a tumour in her breast. She was operated upon by Mr. Barker at University College Hospital on April 7 th, 1880. When she left she knew that she had some enlarged glands in the left armpit, that the operation had failed in its chief purpose, and that she might expect a return of the growth; and this very soon occurred in the cicatrix and neighbouring skin. About three months after the operation (middle of $\mathrm{July}$ ) she began to have pains between her shoulderblades and in both shoulders, though they were neither constant nor very severe. About the same time she also began to have numbness in the inner part of the left wrist and arm, and in the ring and little fingers. This numbness was soon succeeded by severe pain, which kept her "awake for a fortnight." Then it gradually subsided, leaving the whole hand numb. About six weeks ago (beginning of September) she began to feel numbness in the right ring and little fingers and along the inner border of the hand, though to a less marked extent than on the opposite side. About September 24th she began to experience a feeling of numbness in the perinæum, and very soon after in the legs, and then pari passu with the increase of the numbness, and equally on both sides, she lost power over her lower limbs. Thus, without any distinct onset or sudden exacerbation, she found increasing difficulty in moving, so that

1 See "Note sur le contraction idio-musculaire chez les épileptiques," pai" MM. Ch. Féré et H. Lamy, 'Archives de Physiol.,' Juillet, 1889, p. 570. 
by October 1st she was quite unable to move her lower limbs, even in bed. Towards the end of the first week of the paralytic symptoms she had retention of urine, and this persisted for two days after admission to the hospital, so that she suffered from retention for about ten days, and this was succeeded by incontinence. She says also that for about two days before admission the numbness began "to creep up from her waist to her chest."

From the surgical notes it appears that on the patient's admission to the hospital there was a " commencing bedsore on the right side of the sacrum," but this was healed before she was transferred. It is also noted on October 12th that the "patellar tendon-reflex was present and not diminished."

Present state (October 19th).- - Some extracts only as to her condition at this time will be given, as the loss of sensibility was far from complete, and therefore at this period a total transverse softening could not have existed.

Although she had lost flesh, she is still a fairly well-nourished woman; and with the exception of the scar and new growth described below there is no affection of the skin, which is warm, moist, and of a healthy colcur. The left breast is absent, and in its place is a long scar which extends into the axilla, and ends in a loose fold of skin. The scar is nowhere entirely adherent to the chest. There is much hard thickening of the skin in the neighbourhood of the scar, and also upwards to the summit of the shoulder. The tissues in the axilla are indurated so as to form a hard mass there. Temperature varying between $98^{\circ}$ and $99^{\circ}$ since admission.

Spine.-There is an unusual prominence of the last one or two cervical and of the first three or four dorsal vertebræ. There is likewise some tenderness to percussion over them, as well as hyperæsthesia to touch, to pin-prick, and to heat and cold.

There is absolute loss of all power of voluntary movement in the lower extremities. There is no wasting of any of the muscles, and the electrical reactions are about normal. In the upper limbs there is no evident wasting of any muscles, except to a slight amount in the ball of the left little finger. Most of the muscles respond rather more readily on the right than on the left side. She can execute any movement with either arm or forearm except flexion of the wrist on the left side, and on that side the power of flexion of the fingers is so much diminished that she cannot close her hand sufficiently to grasp at all. Grasp, right 19, left 0 . No action of abdominal muscles either voluntarily or during respiration.

There is greatly diminished but not abolished sensibility, in all its modes, over the whole of the left hand, but especially over the little finger and the palmar and inner side of the ring finger. A similar condition exists on the right side only over the little and ring fingers. Similar defects in sensibility exist over both lower extremities, over the abdomen, and over the thorax as high as the fourth interspaces on both 
sides. Above this level sensation to touch, pain, and heat and cold appears to be quite natural.

Reflexes.-The patellar tendon-reflex is absent on both sides. No ankleclonus usually, though occasionally one may be obtained. Plantar reflex very slight. Abdominal reflexes absent.

Bowels habitually constipated; knows when they are about to act, but has no sensation when fæces are actually passing the anus. Urine is voided in gushes at frequent intervals, unaccompanied by sensation. The urine is alkaline and offensive.

November 3rd.-Patient has been complaining for the last twenty-four hours of a good deal of pain down her left arm. The arm and elbow are œdematous and brawny. Temp. $988^{\circ}$, pulse 84 , resp. 22 . Belladonna and glycerine applied to the arm.

The patient was put upon a water-bed a few days after admission, but in spite of every care a bedsore began to form again about the end of the first week in November. About this period also the bladder was ordered to be washed out twice daily with a weak quinine solution. Up to this time the patient's temperature was mostly normal, only occasionally rising to $994^{\circ}$; her appetite also continued good, and she slept fairly well.

December 13th.-The general condition of the patient was carefully re-investigated at this date. From the notes then made I quote the following particulars :

Occasionally she has a little pain in the left thumb, but nowhere else. The left arm is still swollen and odematous. Her power of moving the upper limbs is decidedly less than it was on admission (especially in the left). On this left side the only movements which remain are some amount of flexion and extension at the elbow-joint (not beyond $90^{\circ}$ in one direction or $150^{\circ}$ in the other). On right side can raise hand to head and execute all other movements, but has very little power. Grasp practically $n i l$; when she attempts to grasp the extensors overcome the flexors. Sensibility in the upper limbs is still only affected in the same area as before, and the degree of impairment is not very notably increased.

Lower limbs.-The skin of the lower extremities is remarkably dry and scurfy. Sensibility is now almost completely lost throughout the whole of both lower limbs. Even when the whole hand grasps the thigh or leg no impression is produced. A pin forcibly driven into the thigh produces no distinct sensation; she thinks "there is something moving, but is not sure." [It was noted at an earlier period that "over the anæsthetic areas a pin-prick draws little or no blood."'] Heat and cold produce no impression.

There is still complete inability to move any part of either lower extremity. Reflex action is also entirely abolished in each limb, with the 
exception that forcible scratching of the soles of the feet causes slight movement of the corresponding toes. Temp. $98 \cdot 5^{\circ}$, pulse 62 , resp. 18 . A bedsore has been forming on the sacrum during the last ten days, which has been dressed with an ointment containing $12 \mathrm{grs}$. of carbolic acid to an ounce of vaseline, and subsequently with iodide of starch daily.

January 6 th, 1881 . - The patient was again carefully examined at this date. The condition of the upper extremities was found to be not appreciably different from that recorded above, except that the power of moving the left limb was rather less. It could not be moved at all from the shoulder, and at the elbow there was only a slight power of flexion through $30^{\circ}$ (from $60^{\circ}$ to $90^{\circ}$ ). Very slight movement at wrist and metacarpo-phalangeal articulations; none at phalangeal articulations. In the lower limbs, however, sensibility was now completely abolished; and the note made concerning the reflexes was as follows :- "No reflex action on tickling soles of feet, but on tapping soles of feet smartly with a stethoscope, contraction of muscles of front of leg followed. The same thing occurred on tapping the muscles directly. No ankle-clonus. No patellar reflex."

The reflex evacuation of the bladder, however, still continnes. The notes say, "Patient passes her urine in gushes about every two hours."

There is now loss of all modes of sensibility on the trunk of the body as high as the fouth interspace; also of movement of abdominal muscles and of intercostals to the same level. The breathing is entirely diaphragmatic.

During the last three weeks the patient has lost flesh considerably, but she has not suffered pain, and has slept without morphia. Her appetite for the last two or three days has been very poor, the tongue being coated with a light fur and rather dry.

Over sacrum the bedsore is deeper and more extensive, and covered with slough. The skin around is red and brawny. On the right heel there is a sore about the size of a shilling (which began about two weeks ago), from which a slough is separating. On left heel there is no sore, but the tissues are indurated. Pulse 68, temp. $99^{\circ} 6^{\circ}$; since December 29th it has risen to $101^{\circ}$ or $100^{\circ}$ nearly every day.

19th.-Patient has been still losing flesh since last note, and is sinking gradually. The bedsore over sacrum is spreading, and at one part is covered with a black slough. She has complained of more pain again in the left arm, and has had a quarter of a grain of morphia twice a day. Anorexia is extreme. Pulse 76, resp. 26, temp. 101'2 . The urine has been free from albumen throughout. For the last five days she has been taking extra strong beef-tea, and port wine ziv daily. The latter is now changed to brandy $̧$ iv.

26th. - Since last note patient has been complaining of pain in the right arm from shoulder to thumb, similar to the pain on the other side. She is scarcely able to raise this hand to the head. She can move the elbow 
and wrist, but is unable to grasp. There is still no loss of tactile sensibility except on the ulnar side of the hand. Patient is sinking; she takes very little food and is very drowsy. She often complains of feeling as if she were choking. Since the 18th inst. her temperature has risen nearly every day to some point between $100^{\circ}$ and $101^{\circ}$.

28th.-Patient died last night, sinking very gradually.

Autopsy (14 hours after death). - Whilst opening the spinal canal it was found that at the bottom of the neck and between the shoulders there was a very thick layer of subcutaneous fat, over an inch in some parts, and amongst the fat a whitish new growth. The muscles beneath were not infiltrated in any way, nor were the arches of the vertebræ, though these seemed to be rather unnaturally soft. The posterior and external surface of the spinal dura mater presented a natural appearance throughout; it seemed natural also on transverse section of it (with the spinal cord) just outside the skull. But it was found to be unduly adherent to the bodies of the vertebræ for a length of about five inches in the lower cervical and upper dorsal regions, the adhesion being due to a new growth of whitish colour connecting it with the posterior part of the bodies of the corresponding vertebre. On opening the dura mater laterally and anteriorly the new growth was found not to have made its appearance on the inner surface of this membrane. The lower two thirds of the cervical swelling of the Spinal Cord felt decidedly softer than natural, and opposite its lower extremity (corresponding with the lower margin of adhesion of the dura mater to the bone) the cord showed evidence of extreme wasting; it was here notably flaccid and atrophied, and had an appearance suggestive of pressure, though nothing was found that could have caused pressure. For a distance of about four and a half inches below this point the cord presented a very irregular appearance, owing to the existence of two other areas in which its substance was distinctly softened and atrophied. This was most marked about three and a half inches from the lower end of the cervical swelling, where the cord seems to be even softer and more flaccid than it was above. Immediately below this point, for a distance of about one inch, the cord was also somewhat softer than natural; but below this latter level its consistence seemed to be that of health. On the anterior surface of the cord no large vessels were seen, nor was there any unnatural vascularity ; but on examining its posterior surface the cervical and upper dorsal regions were found to be decidedly more hsperæmic than natural. On this posterior aspect of the cord depressions and irregularities were to be seen similar to those found on its anterior surface.

On cutting through the cervical swelling about its middle, the surface of the section seemed to be decidedly softer than natural; whilst in another section through its lower third all parts of the white substance were found to be somewhat diffluent. In some parts here a semi-fluid pulp could be easily scraped from the cut surface, whilst the grey matter 
was extremely indistinct on both sides. There was, however, no excessive amount of vascularity.

On making another section just below the cervical swelling, at the region of atrophy with softening, the whole substance of the cord was found to be diffluent throughout: it was represented by a thick yellowishwhite fluid. On cutting through the lower atrophied portion, the cord (though softened, flaccid, and atrophied throughout) was found to be not absolutely diffluent.

When sections were made through the cord in the lower dorsal and lumbar regions it was found to be of fairly good consistence throughout. All the sections were, however, decidedly paler than natural, the bloodvessels existing in the grey matter being either smaller or less numerous than usual.

Thorax: On cutting through the integuments it was found that the hardened tissues about the base of the scar corresponded with an infiltrating new growth which has caused distinct adhesion to the ribs. On the inner side of the chest, at about the level of the second and third ribs, the pleura was affected with a whitish growth, and the corresponding portion of the lung was adherent to it; but when torn across the adhesions were found to consist only of fleecy connective tissue. This left pleura contained about twenty ounces of yellowish serum. The lower lobe of the corresponding lung was much compressed and airless, and the lower and posterior parts of the upper lobe were in a very similar state. Only the upper and anterior portions of the upper lobe float in water, other portions sink at once. The right lung presented an old pigmented and puckered patch about three quarters of an inch in diameter at the apex, but there was no other phthisical change, old or recent, nor was there any other notable change about this lung. No trace of cancer exists in either organ. Heart of medium size, containing some ante-mortem clots in the right cavities. Mitral valves slightly thicker than natural ; aortic valves healthy. Muscular substance of left ventricle paler than natural, and its consistence below par. Liver smaller than natural, and some parts of it are unduly tough; no distinct pathological change. Kidneys rather small, somewhat congested, and slightly tougher than natural. Spleen of medium size, rather firm; on section it is seen to be of a uniform dark colour. Uterus : This organ has a small fibroid growth attached to its fundus. Ovaries very thick; fibroid capsules exist, and some whitish cicatricial-like patches within. No distinct evidence of cancer. Bladder : This shows no ulceration, but the mucous membrane presents some distinct patches of inflammation. These do not occupy more than one seventh or one eighth of the whole surface of the bladder. Brain and its membranes fairly healthy; no cancer found in any part of them.

On sawing vertically through the spinal column the bodies of the vertebræ, from the fifth cervical to the second dorsal inclusive, were 
found to contain a yellowish-white, firm growth. This occupied the centre of each body, and was surrounded by soft bone. The body of the seventh cervical vertebra had almost entirely disappeared, its place being taken by new growth adherent to the dura mater; part of this was torn away during removal of the cord from the spinal canal. The bodies of the vertebræ above and below were normal, being firm and of pink colour, and contrasting strongly with those that were diseased. The ribs were not infiltrated with new growth, and there was no distinct evidence to show whether or not the growth in the vertebræ had spread by continuity from the axilla, either along the ribs or along the intercostal spaces.

A mass of lymphatic glands lying in front of the vertebræ below the pancreas was very considerably enlarged. Externally they had a whitish colour, and on section presented all the appearance of being infiltrated with a cancerous new growth. Chains of glands, less enlarged, also extended downwards along the iliac veins into the pelvis.

After the spinal cord had remained in a solution of bichromate of ammonia for some time and had become thoroughly hardened, it was again examined, and with the following results :

Throughout the cervical region of the cord well-marked ascending areas of secondary degeneration are seen in the columns of Goll and in the direct cerebellar tracts; but in addition, from about the commencement of the lower third of the cervical swelling up to rather above its middle, there is a continuous longitudinal tract of softening which occupies the central extremity of the left posterior column, together with the hinder part of the grey commissure and the inner part of the posterior grey cornu on the same side (Fig. 2,a). This area is rather larger below, and diminishes somewhat in its diameter above. The central portions of the area are now occupied by a cavity, whilst at its periphery degenerated cord substance is seen.

A section through the lower third of the cervical swelling shows, in addition to the area above described, three other morbid patches, irregular in shape but having very much the same sectional area (Fig. 2). One occupies an area on the right side closely corresponding with that already described on the left side of the cord, though with no central solution of continuity (b). Another occu- 
pies the hinder portion of the right lateral column $(c)$; while the third is a wedge-shaped area with its base outwards, and coming to the surface about the middle of the left lateral column $(d)$.

FIG. 2.

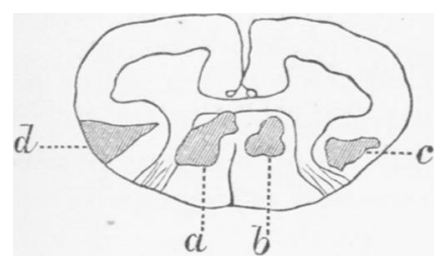

Fia. 3.

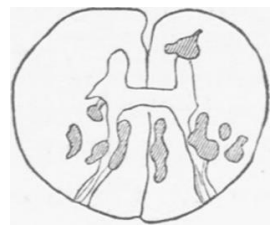

Fig. 4.

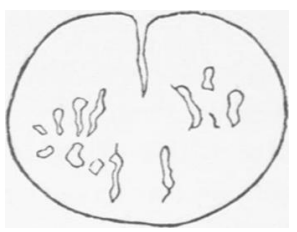

Just below the cervical swelling the cord substance is much wasted, and is diffluent throughout its whole thickness.

For nearly one and a half inches lower down the cord shows no localised lesions except secondary degenerations, though these occupy the greater portion of the white columns of the cord, as both descending and ascending degenerations exist in their most typical form.

The ascending degenerations are due to the fact that a second total transverse softening exists two and a half inches below that in the uppermost dorsal region.

But about one inch above the level of this lower softening the cord begins to show on section, in addition to the above-mentioned areas of secondary degeneration, a number of small opaque white foci (nine in all), agreeing in relative size and distribution with those represented in Fig. 3.

Below the second area of softening for a distance of about one inch the sections of the cord show, in addition to well-marked areas of descending secondary degeneration, a number of very small localised foci of an opaque white colour, very similar in appearance to those which exist above this softened area. In a section three quarters of 
an inch below the softening they have such a disposition as is represented in Fig. 4.

In a section three quarters of an inch below that last described no localised areas of change are seen except areas of descending degeneration, and this holds good for all lower portions of the cord-that is to say, for the last four inches of the dorsal region, and for the whole of the lumbar swelling. The secondary degenerations are present in the lateral columns throughout, and in the dorsal region they are also present in the inner part of the anterior columns, but other portions of the white columns and the grey matter show no signs of disease.

This is an interesting case in very many respects. As to the actual cause of the softening nothing very definite can be said. There were no marks of inflammation about the cord; there was no evidence of thrombosis in any of the larger vessels capable of initiating the softening; and there was no evidence of pressure of any kind, although cancer had obviously involved the lower cervical vertebræ and the corresponding outer surface of the dura mater. On October 19th all movements of the upper limbs were possible except flexion of the wrist on the left side. At this date also it will be observed that although the lower extremities were completely paralysed, sensibility was only greatly impaired. Under these circumstances it is important to remark that the reflexes were not altogether abolished. By December 13th the left arm had become greatly swollen and odematous, and all movements were abolished except slight flexion and extension at the elbow. At this date, though motor power in the legs was completely lost, sensibility to painful impressions was not quite abolished; whilst as to the reflexes it is said, "Reflex action is also entirely abolished in each limb, with the exception that forcible scratching of the soles of the feet causes slight movement of the corresponding toes." By January 6th, however, there was complete sensory as well as motor paralysis of the lower extremities, and now also all the reflexes 
were completely abolished; though the notes say that on tapping the soles of the feet smartly with a stethoscope, contraction of the muscles of the front of leg followedthe same thing occurring, however, on tapping the muscles directly. These were doubtless only two different modes of bringing about a simple idio-muscular contraction. Reflex evacuation of the bladder still occurred, the urine escaping " in gushes at intervals of about two hours." Neither in this nor in the previous case is there any mention of the existence of a girdle sensation. 'The immediate cause of the patient's death here was exhaustion and fever resulting from sloughing bedsores.

Case 3.-H. E-, at. 51, was admitted into University College Hospital under iny care on November 26th, 1884, complaining of loss of power in both legs, but mainly in the right.

Past history.-He has been married twenty-five years; no distinct history of syphilis. He owns to excesses " in drink," especially during his younger days, though they have also occurred occasionally, he says, up to within the early part of this year. In other respects his habits have been regular, and he has always been well fed and clothed. He comes from a healthy and long-lived stock, and there is nothing in his family history to throw light upon his present disease. Till within the last few weeks he has always been a strong, healthy, and well-nourished man, except for two or three slight symptoms referred to below which have been of longer duration.

He says that two years ago, whilst going to his work, he trod on some slippery substance, his right heel slipped, and he fell heavily to the ground. This gave rise to great trembling and faintness at the time. He also says that for a long time, "perhaps two years," he has noticed tremors in the right foot, especially when the heel has been raised, as in resting the toes on a ledge, and that he has for a considerable time complained of pain in the back and a feeling of weakness in the loins.

But the symptoms which have more particularly attracted his attention, and for which he can fix a definite date (viz. the first week in October last), are these :-(1) Bladder troubles; viz. a feeling of tightness about the bladder, and difficulty in expelling his water. (2) The right leg showing a tendency to give way beneath him, and this foot dragging in walking, together with a burning sensation in the right foot and legtroubles which have since extended to the left limb. (3) Coincidently with these symptoms he began to feel a constant desire to defæcate, with inability to do so; but during the frequent severe straining efforts to micturate (often causing sweating and tremors of the whole body) there 
was an occasional involuntary evacuation of fæces. On October 15th, after drinking a pint and a half of ale, he first noticed that his water ran away from him, and it has continued to do so ever since. Previous to his admission he has never been confined to bed; but he has had two rigors, one about five weeks and the other about three weeks since.

Present state.'-Patient is a well-built, well-nourished, and fairly healthy-looking man. Temp. 97. $6^{\circ}$. He walks with a staggering, uncertain gait, and would soon fall unless supported. He keeps both legs stiff, and brings the heels to the ground first. He raises the right foot with most difficulty. He can sit up and turn over in bed readily. He flexes the knees with little force, especially the right. Movements at all the other joints are more natural. Dynamometer, right hand 72, left 56. Sensibility to touch and pain normal over the whole body, but he confuses impressions of heat and cold all over the lower extremities. Plantar reflexes normal on both sides; cremasteric, abdominal, and epigastric cannot be obtained. Ankle-clonus well marked, and knee-jerk exaggerated on both sides. Patient feels a desire to micturate, but has no control whatever over the act. He always passes his water involuntarily directly he begins to move. He is rather costive, but experiences desires to defæcate, and also has some slight voluntary control over the act. His sexual desires are unimpaired, but erections are rare. There are no tremors or wasting of the muscles, but there is great rigidity in those of the lower extremities, especially on the right side. All muscles respond to faradisation, but those of lower not so readily as those of upper extremities. Patient suffers no pain of any kind; he sleeps well, his memory is good, and he has no unnatural cerebral symptoms. The functions of all the cranial nerves are unimpaired. There are no signs of thoravic or abdominal disease.

December 6th.-Patient on getting out of bed last uight found himself unable to stand; his legs were so extremely stiff that he could move his ankles and his knees only to a very slight extent. He also complained of considerable numbness in both legs, but more especially in the right, where the sensation extended as high as the lower part of the abdomen. This morning a soft French catheter was passed, and fifteen ounces of normal acid urine were drawn off. Temp. $984^{\circ}$, pulse 68 .

7th.- Yesterday after a dose of saline aperient he had an involuntary evacuation of the bowels, of which he was quite unconscious. Neither is he conscious now when his urine passes. This morning he complains of a band-like constriction across the abdomen just below the umbilicus, beneath which level his sensibility is less acute than it is above. His legs are extremely stiff, and tend to get drawn up beneath him-and after this occurs they are with difficulty re-extended. At 2 p.m. a soft catheter was again passed, and $5 \mathrm{oz}$. of offensive urine were drawn off.

1 Taken on November $29 t h$. 
His temperature, which had previously been normal, soon after this began to rise, so that at $6 \mathrm{p} . \mathrm{m}$. it was $100 \cdot 8^{\circ}$; at 9.45 it was $101 \cdot 2^{\circ}$, and at 10.20 it had reached its highest point, viz. $103 \cdot 6^{\circ}$. The patient then had a rigor, after which the temperature gradually fell, with profuse sweating.

8th.-On examining the patient this morning the knee-jerks and ankleclonus are found to have disappeared. All rigidity of the legs has likewise disappeared, and they are both now completely paralysed. The pupils, which were equal on admission, have now become unequal, the right being much the smaller of the two. At 3 p.m. the patient shivered, and his temperature, which had dropped to $100^{\circ}$, rose to $102 \cdot 6^{\circ}$ by 5 p.m., though it had again fallen to $99^{\circ}$ by 10 p.m. At 7 p.m. a catheter was passed, and a small quantity of urine drawn off, which was rather offensive but distinctly acid. He was ordered an effervescing saline three times a day, and to omit a mixture containing iodide of potassium and liq. arsenicalis, which he had previously been taking. Spoon diet.

9th.- He has slept fairly well, but he passed one or two motions into the bed during the night. Temp. 99. $6^{\circ}$. This morning he was placed on a water-bed, and his present state was again taken for comparison with that of Nowember 29th.

He has now no voluntary power whatever in his lower extremities, and can neither sit up nor turn over in bed. Movements of upper extremities and of head and neck normal, but the right hand shakes a little when held out. Dynamometer, right hand 65, left 56. Has a feeling as of a constricting band over the abdomen, below the umbilicus, which does not extend to the back. He has complete loss of painful and tactile sensations all over lower extremities and over abdomen as far as margin of thorax in front, and to about the ninth intercostal space in the midaxillary line. Over the same area he is also dead to thermal impressions. At the upper level there is a narrow zone in which impressions are but faintly appreciated. The upper limit of the anæsthetic area has risen considerably within these last few days. Reflexes: plantar can be obtained on both sides; abdominal, cremasteric, and epigastric not obtainable; ankle-clonus and knee-jerks are now completely abolished. Patient has no control whatever over the sphincters; urine dribbles away at short intervals, and he is unconscious of action either of bladder or rectum. He sleeps well. There is no affection of voice or deglutition; he is not emotional, and does not suffer from delirium, coma, or vertigo. He has, however, slight occasional shooting pains over the vertex. The muscles of the lower limbs are completely relaxed; they are not wasted, and there are no tremors; they respond slightly to the weakest faradic current, and readily to a stronger current. Appetite good, no excessive hunger or thirst, no vomiting, tongue clean and fairly moist.

10th.-Patient slept well last night. Temperature this morning $99^{\circ}$; pulse quiet, 72 ; plantar reflexes decidedly exaggerated. Right pupil still 
smaller than left. Since his legs were tested yesterday with the faradic current they have been the seat of some twitchings.

11th.-This morning some of the urine which had slowly dribbled into a test-glass, and was therefore perfectly fresh, was examined. It was very slightly but distinctly alkaline, smelt offensively, and contained a slight trace of albumen.

15th.-Slept well last night, and is fairly comfortable this morning, with the exception of a constricting pain over the xiphoid cartilage. Temperature is now normal, and since the last note it has ranged betweer $97^{\circ}$ and $99^{\circ}$. He has had no more rigors, but continues to be troubled with the twitchings in his legs. This morning patient was given a glass to collect urine, but it took an hour and twenty-five minutes before any was obtained (showing improvement in bladder reflex); and when it did come it was nearly normal in character, distinctly acid, pale, and with no deposit or offensive odour. Has been taking middle diet for the last two days.

17th.-Patient passed a restless night, only dozing off for slight intervals, and this morning he thought he had a slight rigor soon after 7 a m., but it soon passed off. Temp. $984^{\circ}$, pulse 76 .

19th.- Patient has not had much sleep during the night, being troubled a good deal with cough. He expectorates with great difficulty. Temp. $100^{\circ}$, pulse 104. Surface temperature of right leg $93^{\circ}$, of left leg $936^{\circ}$, and of right arm $97^{\circ}$. Mist. Ammon. $\overline{\mathrm{c}}$ Æth. $\mathrm{\jmath j}_{\mathrm{j}}$, ter die.

22nd.-Patient about the same; cough still very troublesome. Temp. $101 \cdot 8^{\circ}$, tongue furred, pulse 96 . Hot fomentations to chest, together with spoon diet, ordered.

23rd.-A bout the same. He passed a restless night. Temp. 102.4 ${ }^{\circ}$, pulse 120, resp. 28 .

24th.-Patient is rather worse; still sleeping badly. The urine has again become offensive. A bedsore over the sacrum, which has been forming for the last few days, had to be poulticed last night, and this morning it is beginning to slough. Temp. $101 \cdot 6^{\circ}$, pulse 120 , resp. 48. At 6 p.m. the temperature had risen to $103^{\circ}$, after which it again fell. Brandy two ounces.

26th. - During the last few days patient has been getting much weaker, though he still takes liquid nourishment fairly well. He has also of late been taking Mist. Ammon. $\overline{\mathbf{c}}$ Ath. every three hours. He has not complained of any pain, though he speaks of a girdle sensation (now higher) about the level of the ensiform cartilage. $H$ is cough has been very troublesome though not so incessant as it was, and there is great impairment of resonance and bronchophony at both bases. He lies on his back in a semi-apathetic condition, constantly groaning. He does not sleep, bromides and chloral at night producing no effect. The urine has been flowing away at more frequent intervals, and has been ammoniacal for the last two days. The bladder has also during the same time been 
washed out with weak Condy's fluid night and morning. Plantar reflex almost abolished on both sides, and both ankle-clonus and knee-jerks still absent on both sides.

At 7 p.m. patient suddenly expired, when being raised to be washed.

Autopsy (fifteen hours after death).-On opening the spinal canal nothing unnatural was seen except that the dura mater in the mid-dorsal region, for a distance of about two inches, was distinctly more vascular than natural, and than it was above and below this level. Large vessels were here seen ramifying over its surface. The anterior surface of the dura mater, however, presented a normal appearance throughout.

When the dura mater was reflected the anterior surface of the spinal cord was, perhaps, rather unnaturally pale, from just below the cervical swelling down to about one inch above the lumbar swelling. The vessels throughout this region were rather less numerous than they were either above or below it, except that near the mid-dorsal region there were some enlarged vessels over the right antero-lateral aspect of the cord. Its posterior surface along its whole length seemed rather paler than natural, except for one enlarged vessel filled with coloured clot just below the mid-dorsal region.

The spinal cord for a distance of two inches, beginning a little above the mid-dorsal region, was greatly diminished in consistence in its whole thickness.

On section through this region of maximum softening the cord substance was found to be somewhat pultaceous throughout its whole thickness, though there was no actual diffluence. The section presented an opaque white colour all over, except that the outline of the grey matter could just be detected. No cut vessels could be seen. On section of the cord an inch and a half lower down its substance was found to be still distinctly softer and more flaccid than natural, but the outline of the grey matter was now well defined. Below this, in the lowest part of the dorsal region and throughout the lumbar swelling, sections of the cord presented a normal appearance but for the fact that it looked distinctly anæmic ; its consistence was also normal.

When sections were made through the middle of the cervical swelling the grey matter and the antero-lateral columns presented a normal appearance, but the columns of Goll were of a more opaque white colour than natural. A section just below the cervical swelling showed two or three large cut ressels in the central region of grey matter and in the right anterior column; and the column of Goll was altered as above mentioned. A section made two inches and a half below the cervical swelling showed the right anterior cornu to be distinctly more vascular than natural, whilst the outline of the grey matter on the opposite side was not apparent. Another section made about an inch above the commencement of marked softening showed the whole surface to be pale and bloodless and of an opaque white colour, resembling that of the columns 
of Goll in the cervical region. A section slightly lower down presented similar appearances except that three enlarged vessels were seen cut across, two in the central end of the left posterior column, and one in the left lateral column.

The brain and its membranes presented nothing unnatural save an undue fulness in the vessels of the former, both on its surface and throughout its substance (this congestion being doubtless due to the patient's mode of death).

The great veins and right cavities of the heart were much distended with blood, and the right ventricle, in addition, contained a large antemortem clot which extended for a short distance into the pulmonary artery. Mitral and aortic valves slightly thicker and more opaque than natural; otherwise nothing unnatural about the heart. Right lung: No adhesions and no fluid in pleura. Posterior border and entire lower lobe of lung were deeply congested and more solid than natural. Section of the upper lobe revealed nothing abnormal; but section of the lower lobe showed it to be of a very dark purple colour, semi-solid, and for the most part non-crepitant. A dark reddish fluid exuded from the cut surface, and excised portions of this lobe sunk in water. Left lung: Posterior part of left lower lobe covered with recent lymph, slightly uniting pleural surfaces; no old adhesions of any kind. Upper lobe presented no unnatural appearances. Lower lobe was in much the same state as that of opposite side, though it was even more completely solid in many parts, and had about the consistence and friability of splenic tissue. Liver: Weight $4 \mathrm{lbs} .4 \mathrm{oz}$. No thickening of capsule. Its cut surface was almost uniform in appearance and paler than natural. Its substance broke down readily on pressure. Right kidney: Weight $7 \frac{1}{2} \mathrm{oz}$. It was congested and its capsule stripped off readily, but its substance was slightly tougher than natural. Left kidney: Weight $8 \frac{1}{2}$ oz. ; congested; its capsule stripped off readily, but its upper portion was extremely dense, resisting the firmest pressure of thumb-nail. Spleen of medium size; presented nothing unnatural. Bladder: Mucous membrane intensely congested; no ulceration.

On examination of the spinal cord after it had been hardened in bichromate of ammonia it was found that for a length of two or three inches, partly above and partly below the mid-dorsal region, diffuse softening existed through the whole of its transverse area, though the different regions were found to be unequally affected in the successive sections that were made. There seemed, in fact, within this longitudinal region of the cord to be a number of small foci of softening affecting different portions of the transverse area of the organ. The effect, 
however, upon the cord above and below the region of softening above mentioned was almost the same as if the whole cord had undergone a total transverse softening in some part of the same region-that is to say, in the lower one and a half inches of the dorsal portion of the cord, and in the lumbar swelling, well-marked and typical areas of descending degeneration were found in the lateral and anterior columns; whilst in the upper dorsal region, through the cervical swelling, and on to the bulb equally typical areas of ascending degeneration were found in the columns of Goll, and in the direct cerebellar tracts. But for the presence of these areas of secondary degeneration the cord seemed quite healthy throughout the lowest dorsal and the lumbar regions, as it did above in the upper dorsal and cervical regions.

For about a week after this patient was admitted to the hospital, whilst the motor paralysis of the lower extremities was incomplete, and their sensibility was but little affected, marked ankle-clonus was present, and the kneejerks were distinctly exaggerated; the plantar reflexes, however, seemed to be about normal, while the cremasteric, abdominal, and epigastric were not to be obtained. By December 9 th he had become completely paralysed in both lower extremities; and the marked rigidity which previously existed in them had now given place to compleie relaxation. At this date, according to the notes, sensibility was wholly abolished in both lower extremities and over the greater part of the abdomen. As to the reflexes, both ankle-clonus and the knee-jerks were completely abolished, though plantar reflexes could still be obtained on both sides. I am inclined to think, however -judging from what occurred in the other cases as well as from the condition of the cord found after death, - that the abolition of sensibility may not have been quite complete in this case. This view is supported by the fact that on the following day the plantar reflexes had become distinctly exaggerated; whilst the notes also say, "Since his legs were tested yesterday with the faradic current 
they have been the seat of some twitchings." And as late as December 15th there is another note to the effect that he was still troubled with "twitchings in his legs." After this he became very ill, with lung symptoms, and no further note was made concerning twitchings, sensibility, or reflexes, except that on the day of his death it is said, " Plantar reflexes almost abolished on both sides, and both ankle-clonus and knee-jerks still absent on both sides." In this case there was a partial girdle sensation encompassing the anterior, but not the posterior part of the body. Although the softening here was extensive in its area it was not carried to the extent of diffluence, and was, in fact, less advanced than in either of the other cases. The cord and its membranes presented no external evidences that the softeuing was due to an inflammatory process. The death of the patient was brought about in the main by a low hypostatic pneumonia.

CASE 4.--Stephen T. H-, xet. 41, a town traveller, was placed under my care in University College Hospital on January 27th, 1880, having been transferred from a surgical ward.

There is nothing of importance in his family history.

Past history.-Patient was formerly an ironmonger, but latterly he has been a town traveller. He married at 21, and his wife has had seven children. He has always been fairly well off, well fed and clothed. He has not had much business anxiety.

Eight years ago patient had smallpox. He has never had rheumatism or scarlet fever. There is no history of syphilis. In June, 1879, he had some pain in his left groin for which he was treated at this hospital, and in the middle of August, whilst stepping into a high gig, he felt a stabbing pain in this groin. At night he discovered a small opening, and a quantity of watery discharge about his dress. He was admitted as an in-patient in October, and left on December 4th. While in the hospital an abscess formed, the size of the palm of the hand, over the lower ribs on the left side, which was opened. When he left the hospital patient says he could walk perfectly well, and had no pains or numbness in any part of his legs.

His present illness began on January 14th. While he was washing himself he suddenly felt his legs give way and he fell down. Both legs failed him, but the left a little more than the right. He was carried to bed, though he afterwards found that he could manage to get out of bed and stumble about for anything he wanted. He could not stand steadily. 
He says he had both pains and burning sensations in his legs, especially the left, though he could feel anything touching him as well as ever.

Two days after this attack the sensibility of both legs began to be impaired simultaneously, though the loss was much greater in the left leg than in the right. The numbness in his legs kept getting worse, and crept up from the knee to the thigh. Patient also now found that he could not bear any weight upon his legs, though when he was lying in bed he could kick them about freely.

He was readinitted into the surgical ward on January 24th, 1880. So far as motility was concerned, he was then in the state above described. He could still feel anyone touching his legs, though not distinctly. The following day he passed his motions involuntarily into the bed. He had paralysis of the bladder also, and a catheter was passed. Startings of the left leg occurred first on the day of his admission, and on January 26th startings were also noted in his right leg. On this same day "exaggerated reflexes" were noted on both sides, as well as loss of sensibility up to the ribs. On the following day he was transferred to my care.

His present state was not thoroughly investigated till January 31st, but the following notes were taken.

January 27th.- Patient has only slight power of voluntary motion in the legs, but there are frequent spasmodic twitchings in both limbs, the legs being forcibly flexed at the knees and hips, and also adducted at the hips. There are sudden reflex movements of the legs when the soles of the feet are tickled. The knee-jerks are exaggerated. Ankle-clonus is exceedingly well marked on both sides, though both it and the kneejerk are rather freer on the right side. There is retention of urine.

29th.-There is absolute paralysis of both legs. There is loss of tactile sensibility in front of both thighs, and on the abdomen as high as midway between the umbilicus and the xiphoid cartilage on the right side and as high as the costal margin on the left side. There is slight sensibility of the soles of the fect, legs, and backs of the thighs. There is no sensation produced by the prick of a pin on the front of the thighs, or over the abdomen in the region above indicated. The prick of a pin is felt, but not as pain, in the feet, legs, and backs of the thighs. These pricks cause reflex movements of the legs. The knee-jerks are absent, and there is no ankle-clonus. Bowels confined, and retention of urine still exists.

30th.-There are spasmodic movements of both legs, though they are much less marked than they were on the 27 th. There are no pains or other subjective symptoms. Temp. $101^{\circ}$, pulse 110, resp. 28.

31st. Present state.-Patient is a well-nourished, well-developed man, though he says he has been stouter than he is at present. $\mathrm{He}$ has no general symptoms of disease. There are no scars or eruptions on the skin except a longitudinal scar running parallel with the ribs, and 
situated between the ninth and tenth ribs on the left side. This was caused by an incision made in November last to let out pus. There is also an opening of a sinus between the left thigh and the scrotum, which still discharges an ichorous fluid.

There are no affections of the cerebral nerves or of the upper extremities.

$\mathrm{He}$ is absolutely unable to move either leg at any joint. The muscles are fairly well developed, moderately firm, and equally so on the two sides. The muscles of thigh, leg, and special muscles of the foot all react well to both faradic and constant currents, and their reactions are equally good on the two sides. Above the umbilicus there is a slight reaction of both recti to both currents. Below the umbilicus no movements of the recti can be obtained with either current. The oblique muscles react fairly well.

Patient feels the touch of the finger on the left foot, leg, and back of the thigh. Similar results are obtained on the right side. The prick of a pin is not felt on the front of the left foot, leg, or thigh, but on the back of the thigh he sometimes feels it as a touch. On the right side he feels the prick of a pin pretty sharply-in fact, as acutely as in the arm. Except on the dorsum and occasionally on the sole of the right foot, he does not feel either heat or cold, and when he does feel them he mistakes heat for cold.

Over the abdomen the touch of the finger is not felt below the level of the umbilicus; sensation is also impaired between the costal margins and the umbilicus. The prick of a pin is not felt below the umbilicus on the left side. On the right side it is felt as low as midway between the umbilicus and the pubes. Above the umbilicus he can feel the cold spoon applied. A hot spoon he can distinguish as warm. He can feel the cold more distinctly, but is not sure whether it is hot or cold. There are no subjective sensations of numbness or pain except some pain in the right knee and the right shoulder, both of which are also painful on movement. There are occasional starting movements of the legs, but these are slight. The knee-jerk and ankle-clonus are absent on both sides. Tickling the soles of the feet and pricking the legs with a needle, although not felt by the patient, cause starting movements of the legs. Otherwise cutaneous reflexes in the legs and abdomen are absent. Temp. $101 \cdot 1^{\circ}$, pulse 122 , respirations 23 .

February 3rd.-The urine is distinctly alkaline. Temp. $102 \cdot 6^{\circ}$ in mouth, $102 \cdot 6^{\circ}$ in left axilla, and $102 \cdot 4^{\circ}$ in left ham.

7th.-The urine now passes very frequently; it does not drop away, but comes in small quantities. Patient still complains of pain in the right shoulder and knee.

8th.-The bowels were opened yesterday several times as the result of an aperient. Patient was not aware when they were going to act. The urine is still voided frequently whenever small quantities collect, but the whole is not expelled, for the catheter passed soon afterwards draws 
off two or three ounces. The urine is less ammoniacal than it was, and it does not contain so much mucus. The calf-muscles are flabby; they do not react so energetically to the faradic current as they should do, but reaction to the constant current is about normal.

10th. - The right knee-joint is swollen and contains fluid. It gives no pain. Patient now feels a touch on the dorsum of the right foot and on the front of the right leg, also slightly on the front of the right thigh. On the back of the right leg and thigh he occasionally feels a touch. Over the whole of the left limb the touch is not felt as well as on the right side. He occasionally feels it, but often says he feels when no one is touching him. The prick of a pin is felt on the right side rather acutely over the whole limb. He feels it most acutely on the calf and back of the thigh, and least on the front of the thigh. On the left side the prick of a pin is felt acutely on the front of the leg. It is felt, but not as a prick, on the front of the thigh, but on the back of both leg and thigh he feels it slightly. He feels the prick slightly to midway between the umbilicus and the pubes, though more acutely on the left side. Above this, sensibility is normal. Patient can now move both legs very slightly, the left a little better than the right. On the left side the movement is caused chiefly by flexing the thigh, slightly by flexing the knee. The movement is very slight, and he cannot lift the limb from the bed. On the right side the movement is caused only by flexing the hip. It is just enough to draw the heel up the bed for about two inches. Tickling the soles of the feet causes marked reflex actions in both legs. There is a slight knee-jerk on the left side, but none on the right. There is also no trace of ankle-clonus on the right side, but on the left side a slight quivering of the foot is felt, though it is hardly enough to be seen. The bladder is still washed out daily with a solution of quinine; the urine has now no ammoniacal odour, and its reaction is acid.

14th.-Patient still retains a slight power of movement in the legs; that of the right leg is very slight, whilst that of the left is more marked. Tactile sensibility is now good in both feet and legs, as well as over backs of thighs. There is slight sensibility on the front of the thighs. This is absent or very slight on lower part of abdomen as high as midway between the umbilicus and pubes. Painful impressions are felt acutely on the right leg and thigh, and slightly on the lower part of the abdomen. These are felt badly on the left leg and thigh and lower part of abdomen. Both the legs move when pricked and when the soles of the feet are irritated. There is a slight knee-jerk on both sides to-day; and there is also a slight ankle-clonus on the right side. Micturition is now performed voluntarily. Patient feels the sensation of wanting to pass water, and has time to get the bottle. He can also pass his water voluntarily when only a small quantity has collected. He now knows also when he is going to have a motion, and has some slight control over the act.

15th.-To-day there is a well-marked knee-jerk on both sides, and 
ankle-clonus has also returned on both sides. The power of moving the legs is not so good; at the time of the examination the patient could not move them at all. When the catheter (which is a soft india-rubber one) is being passed there are rather violent movements of both legs. There are also spontaneous spasmodic movements of the legrs.

17th.-Patient has lost all power of movement in both legs. Sensibility to light touches seems perfect over the whole limb on the right side. Over the left side a touch can be felt, but not so distinctly as on the right side. The slight prick of a pin is felt over the whole of the front of the right leg. He says he feels it more acutely than on the arm. He feels the prick over the whole of the left limb also, but over the front of the thigh it is not felt as pain. Tickling the soles causes well-marked reflex movements of the limbs. Ankle-clonus is well marked, and kneejerks are exaggerated on both sides. Temp. $99 \cdot 6^{\circ}$, pulse 120 , resp. 18 (taken at 10 a.m., but temp. at 6 p.m. $101^{\circ}$ ).

March 7 th. - Since last note patient's temperature at $6 \mathrm{p} . \mathrm{m}$. has rarely been as low as $100^{\circ}$; it has mostly varied between $100.5^{\circ}$ and $102.5^{\circ}$. To-day at the same hour it was $103^{\circ}$. Patient was sick three or four times yesterday, and felt sick all day. There was a considerable flow of pus from the sinus in left groin this morning.

17th.-A small bedsore has appeared on the inner side of the left ankle. Sensibility to tactile impressions is now lost in both lower extremities, and is much impaired over abdomen and chest to the level of nipples. Sensibility to painful impressions is very much impaired over the same area of abdomen and chest, so that as a rule the patient does not feel the prick of a pin. In the lower extremities a deep prick is now and again felt, at other times not, but there is no area to be made out where the sensibility is less impaired than it is at others. The impairment of sensibility is much more marked than it is over the abdomen. There is complete loss of voluntary power over both legs, and very little power in moving the trunk. There is only very slight expansion of the lower part of the chest during inspiration. The knee-jerk is absent on both sides. Ankle-clonus is absent on the right side, but the very slightest quiver of the foot is felt on the left side. The prick of a pin in both legs now and then causes reflex movements. Since the 11 th inst. the temperature in the evening has been a trifle under $100^{\circ}$; but to-day at 6 p.m. it was $101^{\circ}$.

April 28th.-The abscess is discharging again after it had ceased for about a week. The temperature during the last fortnight has been higher, several times reaching $102^{\circ}$ and $101^{\circ}$ in the evening. The pulse has mostly ranged between 120 and 130. Has been taking brandy ziv daily for the last week.

May 14th.-The patient suffered from a profuse perspiration which lasted through the night, and he seems much exhausted this morning. Temp. 99.3 $3^{\circ}$, pulse 144 , resp. 40 .

21st. - Patient has been getting gradually weaker for some days. He 
has had some delirium and the pulse has been failing rapidly. The bedsore over the right trochanter (which has existed for more than a month) has become rapidly worse during the last ten days or more ; it is now very deep and sloughy. That over the left trochanter is only a little less bad. There is also now a very extensive bedsore over the sacrum exposing the bone. Plantar reflexes, knee-jerks, and ankle-clonus were all absent on both sides two days ago. Patient gradually sank and died at 7 p.m.

Autopsy (sixty-six hours after death).-On opening the spinal canal the left side of the arches of some vertebræ in the lower cervical and middorsal region were, on their inner surface, found to be slightly carious, the erosions being filled up by a soft yellowish-white material. A thin layer of a similar material, looking like half-dried pus, was found also on the corresponding external surface of the spinal dura mater. Otherwise the mernbranes of the cord presented nothing unnatural.

The spinal cord itself was damaged during the opening of the spinal canal in the upper dorsal region. In this region it was found to be reduced to a pultaceous mass, and as this was probably the seat of the main pathological change it was difficult to say how much of the softening was due to damage and how much to disease. The external surface of the cord presented no hyper-vascularity, either anteriorly or posteriorly.

On section through the spinal cord at various parts of the cervical swelling there was no distinct evidence of undue softening in any part. The grey matter possessed its usual amount of vascularity. In the upper part of the dorsal region the cord substance was extremely soft and pultaceous throughout its whole thickness, for a length of more than one inch ; whilst above this, as far as the lower end of cervical swelling, the cord seemed rather softer than natural (it might, however, have been due only to the lateness of the autopsy). Sections made through the lower dorsal and the upper lumbar region seemed to show an unnatural amount of softness in the lateral and posterior columns, though it was thought that this also might be a mere post-mortem change owing to the number of hours between death and the autopsy. Sections through the lower part of the lumbar region presented a fairly natural appearance. Viewed externally the lumbar enlargement had a somewhat atrophied appearance.

Brain and its membranes. - The arachnoid was unusually thickened, and generally more opaque than natural. There was also an excess of subarachnoid fluid. The great arteries at the base of the brain were fairly healthy. The hrain showed no naked-eye appearances of disease.

Heart.-The pericardium contained $1 \frac{1}{2} \mathrm{oz}$. of blood-stained fluid. Mitral and aortic valves rather thicker and more opaque than natural. Right lung: This organ was very firmly adherent to the parietes throughout, and there was a thick layer of $15 \mathrm{mph}$ on the posterior part of the parietal pleura. The upper lobe was more solid than natural, and on section it was found to be very odematous, and its tissue very 
unduly tough. In the lower part of this lobe there was a large patch, about an inch in diameter, thickly studded with miliary tubercles. The lower lobe was somewhat solidified throughout, and more congested and friable than natural, but contained notubercle. Left lung: This was firmly adherent about the apex to the parietal pleura. The upper lobe was unduly hard and semi-solid, and was here and there puckered on its surface. On section at a distance of three inches from the apex and downwards, the lung tissue was studded with a number of discrete and aggregated miliary tubercles, the latter forming indurated patches about three quarters of an inch in diameter. In the lower part of this lobe there were also two small, thick-walled cavities, about half an inch in diameter, like the remains of old abscesses. No tubercle in other parts of this lung; but the lower lobe was somewhat congested and solidified throughout, the tissue being also more friable than natural. Liver of medium size, almost uniformly pale everywhere, except for a few areas in which there was some congestion. Consistence below par, and its substance feels greasy. Spleen small, very flaceid; cut surface mottled and grumous-looking. Substance distinctly softer than natural. Kidneys extremely flaccid and unduly pale. The left organ showed considerable inflammation of the pelvis, with deposits of calcareous matter on some portions of its mucous membrane. The left ureter also showed well-marked inflammation throughout. Bladder: It contained a quantity of thick purulent urine. Walls slightly thickened. No ulceration, but radiating away from its neck were lines of slightly inflamed mucous membrane.

Sinuses.-The sinus opening in the left groin just beneath the spermatic cord ran upwards for four inches between the tendons parallel with Poupart's ligament. It was continuous with another sinus running downwards and outwards for about two inches beneath the fascia lata of the left thigh. On cutting through the spermatic cord there was seen, about half an inch from middle line, a sloughy opening, at the bottom of which the probe came into contact with dead bone. Also communicating with this opening there was a sinus which turned round the edge of the adductor longus and there divided into two parts, one running into the adductor magnus, the other arm communicating with a large cavity beneath the adductor longus. This cavity was filled with dirty brown very fœtid pus. It was irregular in form, and lay between the mass of the adductors and the femur. The tip of the small trochanter projected into it, and seemed slightly eroded. A branch of the cavity also passed backwards beneath the neck of the femur, but no " dead bone" could be felt in that situation.

Examination of the spinal cord after it had been hardened in bichromate of potash :

Portions of this cord are unfortunately missing. It 
must have been examined at some previous period either by myself or by one of my assistants, and now no notes as to the results of this examination are to be found. I will, however, enumerate the portions of the cord which remain, and state the nature of the changes of which they are the seat.

(1) A part of the upper third of the cervical swelling. Sections through this part show well-marked ascending degeneration in the columns of Goll and in the lateral columns.

(2) A portion of cord about four inches long from the lower cervical and upper dorsal region, which is much crushed and partly softened.

Sections through the least damaged portions of this show opaque tracts of degenerated tissue occupying in several places the greater part of the transverse area of the cord. On account of the crushing of the cord during its removal, it was impossible to define the extent of the original lesion. From the nature of the lesions above and below, however, in the form of secondary degenerations, it is highly probable that it must have involved the whole thickness of the cord over a certain extent.

(3) The lower dorsal portion of the cord for three inches above the lumbar swelling.

(a) Sections through the upper portion of this fragment show well-marked areas of secondary degeneration in the lateral columns posteriorly, but scarcely any in the anterior columns. The substance also looks white and unhealthy in the peripheral third of both posterior columns. The morbid area is ill-defined in outline, and gradually shades away centrally into healthy-looking tissue.

(b) A section madeaninch and a half lower down presents a very similar appearance. It looks as if there had been slight softening in the peripheral portions of the posterior columns.

(c) A section just above the lumbar swelling shows a similar state of the lateral and of the posterior columns. No distinct change is to be seen in the anterior columns, 
in the grey matter, or in any other portion of the cord.

(4) The upper portion of the lumbar swelling.

Sections here show some distinct softening of the peripheral third of the posterior columns, in addition to wellmarked secondary degenerations in the posterior part of the lateral columns.

(5) Rather more than the lower third of the lumbar swelling.

Sections through this present a healthy appearance, except for very small areas of secondary degeneration in the lateral columns. There is no evidence here of softening of the posterior columns, and the grey matter presents a healthy appearance.

Nothing is known by me as to the cause of the original pain in the groin in June, 1879, and the discharge which first occurred therefrom two months later. The results of the post-mortem examination showed that the opening in the groin was in connection with several very extensive sinuses associated with foul collections of pus and with necrosed bone. It was made probable also that the large abscess that formed over the lower left ribs during his stay in the hospital previous to December, and which was opened at that time, was connected with an offset from the same system of sinuses. Subsequently there came the softening of the spinal cord and the development of tubercle in the lungs, as well as a suppurative caries of the laminæ of some of the cervical and upper dorsal vertebræ. How far either of these processes had to do with the actual development of the softening of the spinal cord is, of course, altogether uncertain. It is worthy of notice, however, that the very abrupt onset of the symptoms of paralysis on June 14th, in the absence of all post-mortem evidence of a hæmorrhage, pointed strongly to these first symptoms being due to a vascular occlusion of some kind. No conditions favouring embolism were met with after death; but it seems just possible that there may have been a thrombosis occurring rather suddenly, and 
due, perhaps, to endarteritis set up in connection with some amount of blood-poisoning, consequent upon the unhealthy suppuration in the sinuses. Certainly in this, as in the other cases, there were no external signs of an inflammatory process in connection with the upper dorsal region of the cord or its membranes.

The extent of the original lesion in the upper and middorsal regions of the cord could not be determined, owing to the damage which it had received at the time of removal, as well as to the fact that I could find no record of the previous examination, doubtless made, of certain portions of the organ that were missing. As it happens, this is of comparatively little importance in regard to my main purpose in this paper, because of the fact that a superficial softening of the posterior columns of the cord (the only lesion, apart from descending secondary degenerations, existing in the last three inches of the dorsal region) also extended into the upper third of the lumbar swelling. For though the grey matter in both the upper and the lower parts of the lumbar swelling presented no appearance of disease, this case will not, perhaps, be considered to have the same cogency as either of the others. Yet in some respects it has supplied very important evidence as to concomitant variations between slight degrees of sensibility persisting and slight manifestations of reflex activity. Thus, when the paralysis was incomplete there was rigidity of the lower extremities, together with distinctly exaggerated reflexes; but by January 31 st the motor paralysis had become absolute, and sensibility in all its modes had become very greatly impaired, and at this date the knee-jerks and ankle-clonus were absent on both sides, though starting movements of the legs could be induced by pin-pricks on the legs, or by tickling the soles of the feet. Later on, while the motor paralysis was absolute on February 17th, sensibility had very greatly improved. The notes say, "Sensibility to light touches seems perfect over the whole limb. Over the left side a touch can be felt, but not so distinctly as over the right 
side;" and with this state of things knee-jerks, ankleclonus, and plantar reflexes had become well marked on both sides. By March 17th, however, sensibility was again almost completely abolished in both lower extremities; that to tactile impressions was in fact completely lost, but the sensibility to a deep prick was not absolutely destroyed. There was still complete motor paralysis, but in regard to the reflexes the notes say, "The knee-jerk is absent on both sides. Ankle-clonus is absent on the right side, but the very slightest quiver of the foot is to be felt on the left side. The prick of a pin in both legs now and then causes reflex movements." Unfortunately no mention is made as to the plantar reflexes, but this may not unfairly be taken as an indication of their absence; had they been present it would almost certainly have been recorded. Death occurred in the main from exhaustion with bad bedsores after the paralysis had lasted for seventeen weeks. During the course of this illness there were frequent high temperatures, due in part to the unhealthy suppuration going on (together with other changes in the extensive system of sinuses), and partly to the development of tubercle in the lungs.

It has recently come to my knowledge that the statements I had made in 1882, and afterwards in my work on ' Paralyses ; Cerebral, Spinal, and Bulbar,' as to the condition of the reflexes in complete transverse lesions, had been received by some with not a little incredulity. It seemed desirable, moreover, that the detailed evidence on which the statements were founded should be published. I accordingly undertook this task.

Three classes of objections, belonging to one or other of the following categories, have been raised by different friends.

(1) It has been said that abolition of the reflexes in total transverse lesions would be a direct consequence of shock, and that if the patient only lived long enough after the establishment of the lesion the reflexes would return; 
further, that with the establishment of well-marked secondary degenerations in the lateral columns, more or less of rigidity would supervene in the previously flaccid limbs.

To this objection the cases now recorded (even without the support which will be given by several other cases about to be referred to) seem to me to afford a complete answer. The duration of shock in most cases of disease or injury to the spinal cord may fairly enough be said to vary between a few hours and, at most, a few days. But in the four cases here recorded anything like shock was a very unobtrusive feature, and the patients remained under observation for considerable but variable periods; it was with them a question of weeks rather than of days. Thus, in Case 1, the duration of the paralysis was eight weeks; in Case 2 it was seventeen weeks; in Case 3 it was nineteen days; and in Case 4 it was seventeen weeks. And although there is not in all of the cases a record of the condition of the reflexes up to the termination of the illness, my memory enables me to say most definitely that the limbs in all remained in a condition of flaccid paralysis, with no sign of rigidity, even up to the end.

(2) It has been said, again, that no such abolition of reflexes would occur unless the lumbar region of the cord had been also the seat of damage; some have even seemed inclined to go so far in support of their opinion as to say that the fact of the reflexes continuing to be abolished after the effects of shock had passed off was of itself evidence that the lumbar swelling had also been the seat of some lesion, so sure were they as to the truth of their general principles. A reasoner of this latter type is often hard to be convinced. I venture to think, however, that I have brought forward some valid evidence to show that, at all events in three of my cases, the lumbar swelling was free from disease even though the reflexes were abolished, and all signs of shock had entirely disappeared. This kind of objection is, however, even more completely met by a record of what has happened in certain cases of fracture-dislocation occurring in previously healthy persons 
in the cervical or upper dorsal region of the cord, to which I shall presently refer. Here a localised traumatism only has existed in one of these regions, and there has been no reason for supposing the existence of an independent lesion or disease in the lumbar region of the cord.

(3) Lastly, incredulity has been expressed in regard to the truth of my statements, on the alleged grounds that no such flaccidity of limbs and abolition of reflexes had existed in cases either known to or previously under the care of such critics; there had rather been, they said, the very opposite condition of things, viz. rigidity with exaggeration of reflexes. In regard to objections of this order, all I can say is that when these critics have been asked to give me the references to any such cases as they have described, either published or unpublished, the cases to which my attention has been called have, as yet, always proved unsatisfactory-that is, there has been evidence either of a clinical or of a pathological order to show that the cases referred to have not been in reality cases of total transverse lesion. In some of them it has appeared from the notes of such cases that sensibility has only been " impaired," not abolished ; whilst in others post-mortem evidence has shown only a partial transverse destruction of the cord at the seat of disease, and the existence of many more or less normal nerve-fibres surrounded by others which have become broken up, or else by a more or less developed overgrowth of connective tissue in the cases that have been of a more chronic order.

The necessity of accepting any such cases as these last referred to, only with the greatest reserve, is shown by the records of a very remarkable case of so-called " compression-myelitis" described by Charcot. The patient referred to died two years after she had been cured of a paraplegia which had been associated with vertebral disease and angular curvature, and the condition revealed by the autopsy is thus described. Charcot says," "The

1 - Ifeçons sur les maladies du système nerveux,' tome ii, 3me ed., p. 93, 1880 . 
spinal cord in this woman at the level where compression had existed in consequence of Pott's disease was no larger than a goose-quill, and when cut its section was not more than about one third of that of a healthy spinal cord examined in the same region. Its consistence was very firm, and its colour grey; in short, the spinal cord presented all the appearance of the most advanced sclerosis (pl. iii, fig. 1, $d$ ). . . . . Above and below this narrowed portion the white columns were occupied by grey tracts of secondary degeneration. . . . . Between the appearances presented by the narrowed portion of the cord when examined by the naked eye only, and the phenomena observed during life, there existed, as it seemed, a most striking and singular contradiction. The restoration of functions, as I have said, had been perfect at the time of death, and yet at this time the cord, if we were not to rely wholly upon the information yielded by microscopical examination, was the seat of lesions so profound that it appeared literally interrupted at one point in its course by a cord of sclerosed tissue, in which one would have thought that every trace of nerve-element had disappeared. . . . Histology, however, shows us that the contradiction is not real. The connective-tissue substitution is here only apparent. In the midst of the very thick and dense tracts of fibrous tissue which gave to this portion of the spinal cord its grey colour and its dense consistence, the microscope showed a pretty large quantity of nerve-tubes provided with their axis-cylinder and their envelope of myeline, and consequently quite regularly and normally constituted. . . . . It was by the intermediation of these nerve-fibres that, during life, the behests of the will and sensory impressions had been conducted."

This case of Charcot's is undoubtedly a very remarkable one, and difficult enough in many ways (as he points out) to understand; but it suffices admirably to show the very great reserve with which cases of this order should be regarded as cases of total transverse lesions when we 
are concerned with the strict estimation of the symptomatology of this latter condition. It is clear that we must not, as I was myself originally disposed to do, accept the mere fact of the existence above and below a given lesion of the best developed ascending and descending secondary degenerations as evidence that the lesion in question was a total transverse one. A very little reflection suffices to show the fallacy of this view, and that such well-developed secondary degenerations in the white columns may exist with all degrees of partial destruction of grey matter; nay, it is conceivable, though not likely ever to occur, that such secondary degenerations should exist in their fullest development without any primary disease of the grey matter at all.

Thus it becomes clear that there are two classes of cases more especially in which we may search for the revelation of the true symptomatology attaching to total transverse lesions of the spinal cord. The first of these classes would comprise the cases $(a)$ in which a condition of diffluence, or something approaching thereto, has been induced through the whole thickness of the spinal cord in some limited portion of the cervical or upper dorsal region, either by simple thrombotic softening or by actual acute myelitis, provided that in such cases the patient lives sufficiently long after the establishment of the disease. This is the class of cases which $I$ have hitherto considered in this paper. I have, as yet, not been fortunate enough to find a record of any similar cases by other observers, and possibly very few will be found. The first case that occurred in my practice in 1879 struck me very much, and it sufficed thoroughly to rouse my attention in each subsequent case, simply because the phenomena were quite contrary to what I should have expected to occur. I sought, therefore, to obtain good evidence, during life, as to the degree of preservation of the reflexes in conjunction with different degrees of anæsthesia; and, after death, as to the degree of completeness of the lesion. In the clinical examination of these cases 
I was aided by a series of excellent observers who were, at the periods referred to, my house-physicians. The observers thus associated with me in the investigation of these cases, and to whom I am indebted for many accurate and painstaking notes, were Mr. Bilton Pollard, Dr. Dawson Williams, Dr. Henry Carr-Maudsley, Dr. William Pasteur, and Dr. J. Walter Carr. I say that possibly few such observations will be found on record because, in the first place, we should be limited to observations that may have been reported during the last ten or twelve years. We could not go back to older records - to periods, that is, when it was not the custom systematically to detail the condition of the various reflexes. Again, for evidence bearing upon this question we should be limited to such cases as lived sufficiently long to enable us fairly to eliminate the possible effects of shock; to cases which were, moreover, fully reported from the point of view of the exact condition of the reflexes in association with different degrees of impairment or abolition of sensibility; and lastly, to cases in which there had been an autopsy and a determination of the question whether the lesion had or had not been one of the total transverse order.

Since the above was written my colleague Dr. Ormerod has kindly brought to my notice one such case of total transverse softening, which occurred last year in the practice of Dr. Gee at St. Bartholomew's Hospital, and in which he had made the autopsy. I have to thank Dr. Gee for permission to use the notes of this case, for an abstract of which I am indebted to Dr. Ormerod.

CASE 5.-A. M. F-, æt. 26, a draper's assistant, was admitted on February 26th, 1889. On February 21st he had complained of pain in the middle of the back, with a feeling of constriction around the chest. Two days afterwards he was worse, and on the evening of February 24th his legs became weak, and soon afterwards numb, whilst the paralysis in two to three hours became complete. There was also retention of urine, and constant vomiting, previous to admission.

State on admission.--Paraplegia reaching to about third dorsal nerve ; 
anæsthesia to the same level. No superficial or deep reflexes. Retention of urine. Bedsore (third dar).

[The above is Dr. Gee's " clinical abstract." What follow, Dr. Ormerod tells me, are extracts from the house-physician's notes-Mr. Rivers up to April 1st, afterwards Mr. Symonds, "both very careful and good observers." Dr. Ormerod adds, "The absence of the knee-jerks did, as I know, attract particular attention." ]

March 5th.-Incontinence of urine began.

8th.-Patellar reflex present, but very slight. No plantar reflex.

10th, 12th, and 14th. - No knee-jerks obtained. The electrical reactions of the anterior tibial muscles gave the following results :-Faradic irritability fairly good, rather stronger current required than normal; reaction not quite so good as on admission. Some increase of galvanic irritability, but K.C.C. greater than A.C.C., though the difference between them is less than in a normal musele.

16th.-Knee-jerks present this morning, more in right leg.

19th.-No knee-jerk.

22nd.-Legs jerk a little on being washed.

23rd.-Plantar reflex well marked. More sensation in legs.

April 10th.-Reflex movements of legs increased; they often become drawn up when not being touched. Little or no sensation in legs. No knee-jerks.

[In reference to the notes concerning sensibility on March 23rd, April 10th, and May 12th, Dr. Ormerod writes, "This appears to refer to sensation of touch; no special note was made as to sense of pain, temperature, \&c."]

May 12th.-Involuntary contractions of the legs, causing them to be completely flexed, are more marked; they move at the least irritation to the skin. No knee-jerks. No sensation in legs. The anæsthesia now reaches up to the lower border of the sternum. Skin reflexes on abdomen not present.

June 1st. - No knee-jerks.

10th.-Patient died of exhaustion in connection with bedsores and bladder troubles. "The autopsy showed softening of the cord, involving the whole section apparently, the maximum amount being at the level of the third dorsal segment." It extended in length for about two inches. After hardening the cord, Dr. Ormerod says, "The lumbar. region was found to be normal except for descending degenerations."

This case affords a valuable confirmation of the truth of my observations. The state of the lower extremities, and their condition as to reflexes and twitching movements, agrees in the closest manner with what was found at different times to exist in my Cases 3 and 4, where it seems certain that the loss of sensibility though nearly 
was not absolutely complete. There was the same kind of spontaneous drawing up of the legs, with twitchings when the limbs were touched or pricked. Then, again, some return of tactile sensibility was noted in Dr. Gee's case on March 23rd; and, as Dr. Ormerod points out, no special notes were made as to the patient's insensibility to painful impressions. The notes of my own Case 4, for March 17, however, show that such movements of the legs co-existed with an incompletely abolished sensibility to pain. Yet in my case, as in Dr. Gee's, there was at the autopsy, "apparently" a total transverse lesion. No rigidity of limbs seems to have existed in this case: in reply to my question Dr. Ormerod writes, "No rigidity at first; no mention of rigidity afterwards, unless the ' involuntary contractions' be taken as a form of rigidity." But, as above pointed out, there is reason to believe that these involuntary contractions co-existed with a severance not quite complete of the spinal cord from the brain. Further, in my Cases 1 and 2, in which the severance of the cord from the brain was undoubtedly complete, the limbs were altogether flaccid, and showed neither spontaneous nor reflex contractions of any kind.

The second class of cases in which we may expect to obtain the true symptomatology of total transverse lesions of the spinal cord is represented by $(b)$ fracture-dislocations of the vertebræ, associated with complete but limited crushing lesions of the cord, in patients who live long enough for the immediate effects of shock to subside. The following are recorded cases of this type which I have met with, together with three unpublished cases that have been kindly brought to my notice by my colleague, Dr. Tooth.

1. A case recorded by Dr. Tooth ('St. Bartholomew's Hospital Reports,' vol. xxi, 1885, p. 140) of a man who had fallen from a scaffold, resulting in a fracture-dislocation of the fifth and sixth dorsal vertebræ with complete transverse crushing of the cord opposite the former vertebra. "It had the appearance of having been cut across without injury to the membranes." This man lived twenty weeks and four days after the accident. 
During life there was total paralysis, with loss of sensibility, in the lower extremities, and in the trunk to the level of the sixth ribs. "No kneejerk, ankle-clonus, cremasteric or abdominal reflex could be elicited on admission, but the epigastric reflex was present on the right side. Two months after admission it was noted that on pinching the lower part of the thigh the hamstring muscles contracted, but there was no sole reflex. The state of the deep reflexes was unfortunately not noted at this time."' Towards the close of his paper Dr. Tooth adds these words: "A curious and hitherto unexplained point in the symptomatology is the complete abolition of all reflexes, superficial and deep, below the lesion shortly after the injury."

2. A case recorded by Kahler and Pick ('Archiv für Psychiatrie,' 1880, p. 297). J. J-, æt. 65, on March 9th, 1878, fell from a height and struck the back of his neck against a beam, whereby he sustained a fracture-dislocation at about the level of the sixth cervical vertebra. His lower extremities and trunk were at once completely paralysed. Sensibility was at first lost to the level of the knees, but the anæsthesia spread upwards during the next two or three days. On examination ten days after the accident (March 19th) his upper extremities were found to be partially paralysed. His breathing was diaphragmatic, and the lower extremities were absolutely paralysed. There was no rigidity; all the muscles were quite flaccid, though not wasted. All modes of sensibility were abolished to the level of the upper part of the thorax. All the reflexes were abolished in the lower extremities except the plantar, which were very weak. The cremasteric and abdominal reflexes were also absent. No subsequent record as to reflexes. Death occurred on the serenteenth day, and at the autopsy the spinal cord was found completely compressed between the sixth and the seventh cervical nerves. There was no damage to the lower parts of the cord, which appeared to be in all respects healthy.

3. Dr. Thorburn's Case 1, recorded in 'Brain,' January, 1887, p. 511. This was also a case of fracture-dislocation, in which there was complete paralysis of all nerves below the fifth cervical, with corresponding loss of motion and sensibility. The man lived for twenty-five days after the accident, and it is said concerning this patient, "Both cutaneous reflexes and tendon reactions were absent throughout." At the autopsy the cord was found to be compressed for a quarter of an inch, and softened for one to two inches above and below, but, it is said, " the rest of the cord was healthy."

4. Dr. Thorburn's Case 3, recorded in 'Brain,' October, 1888, p. 294. This was a case of fracture-dislocation between the fifth and sixth cervical vertebræ, caused by a fall from a waggon. There was absolute paralysis of the legs and trunk, with anæsthesia extending to the level of the third rib in front. He was carefully examined by Dr. 'Thorburn between

I In my cases ankle-clonus and knee-jerks have always disappeared before the sole reflex. 
eighteen and twenty hours after the accident and immediate onset of the paralysis, there having been no loss of consciousness at the time. At this time his temperature was normal, the skin was dry and warm, the pulse was 66 and feeble, whilst the respirations were 18 per minute. All signs of shock seem then to have passed off, but the condition of the reflexes was thus noted:-_" The knee-jerk and plantar, cremasteric, gluteal, and epigastric reflexes were absent." $\mathrm{He}$ was operated upon about twenty-four hours after the injury, and just within a subsequent similar period he died. At the autopsy it was found that " the dura mater was uninjured, but the cord was flattened opposite the seat of injury, and was much contused for about an inch above and below, containing hæmorrhages in its substance and in the central canal ; elsewhere its structure was normal."

5. Dr. Thorburn's Case 4, recorded in 'Brain,' October, 1888, p. 296. This man, about 2.30 p.m. on March 25th, 1887, had another man seated upon his shoulders, when he was pushed backwards against a high counter, and his neck was twisted by the man falling from his shoulders. "For the first few minutes he only noticed pain in the back of the neck, but then his legs began to feel weak, and he lay down; within ten minutes the lower limbs were completely paralysed and insensitive, and he found that he could not straighten the left forearm." The temperature at 4 p.m. was $94 \cdot 2^{\circ}$, at 8 p.m. $97 \cdot 6^{\circ}$, at midnight (that is, nine and a half hours after the injury) it was $99 \cdot 2^{\circ}$, near which point it remained for some days. The motor paralysis was complete, but the loss of sensation was not absolute in the lower extremities. Below the third ribs " there was absolute analgesia, but a vague sensation was conveyed by tickling." The above notes were made on the following morning-viz. about twenty hours after the injury; and for the same period there is this record: "There were no superficial reflexes nor tendon reactions." From the eighth to the eleventh day after the injury, it was noted that "sensation in the trunk and lower limbs seemed to improve slightly." No subsequent note was made as to the sensibility, but on the fifteenth day there is a note saying, "We found distinct knee-jerk on the right side, and on the left a slight reaction could be obtained." $\mathrm{A}$ few days after this the patient's temperature began to rise, and he soon died from pneumonia. At the autopsy the body of the fifth cervical vertebra was found to be slightly dislocated forwards. Some blood was effused into the spinal canal at this level, and the cord was here also compressed for about one inch, but in other parts of the cord nothing unnatural was found. In this case all shock seemed to have passed off at the time the note was made concerning the reflexes; their return to some extent at a later period, coincidently with some improvement in sensibility, is quite in accordance with my own observations.

1 It is quite possible, therefore, that some amount of sensibility still persisted. 
6. Dr. Thorburn's Case 7, recorded in 'Brain,' October, 1888, p. 305. This man, when intoxicated, had fallen from a gallery ten feet in height. He was examined by Dr. Thorburn nearly twenty-four hours after his admission, when, apparently, symptoms of shock had passed off, seeing that his pulse was 80 , and his temperature $99 \cdot 4^{\circ}$. The lower limbs and trunk were completely paralysed, the respiration being diaphragmatic. The lower limbs were also said to be completely ancesthetic, as well as the trunk to the level of the second rib in front. "Superficial and tendon-reflexes were all absent." On the following morning, some twelve or more hours later, the patient being in a very similar general condition, the following additional note was made concerning the reflexes :- "The plantar, cremasteric, abdominal, and epigastric reflexes, and the tendon reactions at the ankle, knee, wrist, and elbow, were all absent." 'This patient died on the tenth day, but no further notes were recorded as to the reflexes. At the autopsy the seventh cervical vertebra was found to be displaced forwards, and the "cord was compressed at the level of the first dorsal vertebra, and softened for a short distance above and below the site of compression, its centre being occupied by an effusion of blood reaching as high as the fifth cervical nerve-roots, in the form of a narrow cone."

7. Case of A. P-, x.t. 18, admitted into St. Bartholomew's Hospital under the care of $\mathrm{Mr}$. Willett on $\mathrm{June} 17 \mathrm{th}, 1886$. This young man had fallen from a height, and had sustained a fracture-dislocation of the seventh cervical vertebra (see 'Lancet,' 1887, pt. ii, p. 261 ; and 'Tooth, ' On Secondary Degenerations of the Spinal Cord,' 1889, p. 30).

On admission there was some loss of sensation and paresis in the arms, but complete loss of sensation and paralysis below a line drawn round the body about three inches above the nipples. The absolute loss of sensibility is strongly attested by the fact that manipulation of a fracture of the thigh, sustained at the same time as the spinal fracture, gave rise to no signs of pain. There was complete loss of all reflex es below the lesionknee-jerks and the cremasteric and plantar reflexes having been particularly looked for. This absence of reflexes continued to the end, rather over six months. No trace of rigidity of muscles was observed, and no note was made of the existence of involuntary twitchings. Death occurred on January 26th, 1887, and at the autopsy a total transverse lesion was found between the eighth cervical and the first dorsal nerveroots (see Tooth, loc. cit., Fig. $\boldsymbol{7}$ ), whilst in the lower portions of the cord only well-marked secondary degenerations existed.'

8. Case of E. T-, at. 4:2, admitted into St. Bartholomew's Hospital under the care of Mr. Langton on October 17th, 1887. The patient had sustained a fracture-dislocation of the sixth cervical vertebra, and on

1 For additional details concerning this case, as well as for the notes of the next two cases, which $I$ have received permission from $M_{r}$. Langton and Mr. Willett to make use of, I am indebted to the kindness of my colleague, Dr. Tooth. 
admission the lower limbs were said to be quite paralysed and anæsthetic. There was also absence of reflexes. On November 7 th it was noted that the sole reflexes were well marked, and that the right knee-jerk had returned, but feebly; the left was not tried. Death occurred on Norember 2.1th, and in recrard to the spinal cord Dr. Tooth sars, "On section at the point of injury the cord appeared to be completely crushed, and no fibres could be seen in carmine-stained specimens; Weigert's method was not used." ('This is not a very conclusive case, I merely quote it for what it is worth; it at least suffices to show that there was no exaggeration of reflexes.)

9. Case of T. B-, xt. 45, admitted into St. Bartholomew's Hospital under the care of Mr. Willett on August 7th, 1888. This was a case of fracture-dislocation at about the fourtl cervical vertebra. There was complete paralysis of the lower extremities, and more or less of the upper extremities. Complete anæsthesia existed below the level of the fifth rib, and there was also considerable affection of sensibility in the arms. There was a total absence of tendon-jerks in the arms and legs. This patient died more than six weeks after admission (on September 25th), but in the notes furnished to me Dr. Tooth says, "Neither sensation, motion, nor reflexes returned. No note is made as to rigidity, but $\mathrm{Mr}$. Bowlby is quite sure that there was none. Owing to the great difficulty in obtaining a post-mortem examination the cord was not all removed. $\mathrm{Mr}$. Bowlby removed it to the level of the fifth cervical vertebra, thinking that that would include the lesion, but on examination the cord shored only descending degenerations. There was therefore no opportunity of examining the crushed spot." The lumbar region was, however, found to be quite healthy except for descending degenerations.

If we were to look at these cases of fracture dislocation alone, there might be reason to fear that in some of them at least the suppression of the reflexes had been entailed by shock. The fact, however, that in other of these cases a similar abolition persisted long after there could have been any reasonable grounds for attributing the phenomena to shock, tends to eliminate our reserve in this direction, as also does the fact that the same abolition persisted week after week in the cases of disease which I have recorded, as well as in Dr. Gee's case, where from first to last there had been no symptoms of shock at all.

Similarly, if we were to look to my cases alone it would be open to the hypercritical-in spite of all appearances to the contrary - to maintain that there might have been lesions more or less minute in the lumbar swelling of the 
cord, to which the abolition of the reflexes was really to be ascribed. But such an explanation loses much of any force that it might have possessed when applied to superficially observed cases, and becomes almost wholly invalid when applied to the other series of cases, viz. those in which previously healthy persons become the subjects of a local and purely accidental damage to a part of the spinal cord far removed from the lumbar region.

The two sets of cases, therefore, mutually illustrate one another, and by their combination tend all the more strongly to support my position that in total transverse lesions of the spinal cord we may expect, contrary to previous views, to find that both superficial and deep reflexes will be abolished.

It will be needless for me now to sum up and recapitulate the symptoms of such lesions as they occur in the mid-dorsal region. I have nothing definite to add, and no distinct alterations to make in the account, based upon careful and repeated observations, given in Quain's ' Dictionary of Medicine' in 1882, and which is in part reproduced here on pp. 153-155. I would only call attention to the fact that the plantar reflex, as a rule, disappears after ankle-clonus and the knee-jerk in cases where all three have pre-existed-that it is, in fact, the last of the superficial or deep reflexes to be obtained; and that what is termed "idin-muscular contractility" (p. 167) may be met with even long after the plantar reflex has ceased to be obtainable. Then, again, in regard to the organic reflexes, it seems clear that two of them not unfrequently persist in these cases of total transverse lesion. We have seen, for instance, that in many cases when a certain amount of urine has collected in the bladder, this organ will contract sufficiently to expel its contents in part-the urine thus escaping "in gushes" at intervals of two or three hours. Again, though obstinate constipation is the rule in these cases, and there is no evidence that the mere accumulation of its own proper excreta will, as in the case of the bladder, lead to reflex contractions of the intestinal tube 
adequate to bring about even partial expulsion of. its contents, yet, when a stronger stimulus is added, in the form of some purgative or large enema, the reflex activity of the intestine becomes adequately roused-it is roused, moreover, under conditions where all cerebral control is lost, so that complete incontinence results so long as the extra stimulus lasts.

Besides its importance as a mere scientific problem in symptomatology, this question as to the persistence or abolition of reflexes in lower parts of the body in cases of total transverse lesions of the spinal cord is also one of great interest and importance in reference to a point in diagnosis, and no less so in regard to the pathogenesis of certain nervous states hard to be explained.

The problem in diagnosis is, as to the means which we possess of ascertaining during life the lower limits of a lesion in the spinal cord, where either it or another higher up has produced, at a particular level, a total transverse destruction of the organ. The conclusion to which we have now arrived, in regard to the conditions under which reflexes are abolished, impose limits upon our powers in this direction not hitherto anticipated. To this question, however, I have already referred (p. 157).

The question of pathogenesis is one which I have elsewhere $^{1}$ treated somewhat at length in a section entitled "The causation of contracture, ankle-clonus, and exaggerated knee-jerk; and the extent to which they are dependent upon cerebellar influence."

The first person, I believe, to start the notion that unrestrained cerebellar influence was largely concerned with the production of rigidities and exaggerated reflexes was Dr. Hughlings Jackson. This was done in a very brief communication in the 'Medical Examiner' for April 5th, 1877, though he has since referred to and developed the same doctrine in two or three other communications. ${ }^{2}$

1 ' Paralyses ; Cerebral, Bulbar, and Spinal,' 1886, pp. 216-229.

2 'Med. Examiner,' March 28th, 1878; 'Med. Times and Gaz.,' Feb. 12th, 1881. 
The difficulties standing in the way of the acceptance of some such hypothesis as this of Dr. Hughlings Jackson were greatly diminished, I venture to think, by my observations as to the abolition of rigidity and exaggerated reflexes in total transverse lesions of the spinal cord. When cerebral motor influence alone is cut off, it is an admitted fact that we soon have to do with conditions of rigidity and greatly exaggerated reflexes in the paralysed parts; but as soon as the remaining connections of the encephalon with the lower half of the spinal cord are completely severed, as they are in total transverse lesions, there is at once an abolition of all rigidity and of the superficial and deep reflexes. What can be the cause of this complete change in the condition of the limbs? Seeing that the cerebral motor influence was previously cut off, it would seem that the abolition of the rigidity and of the reflexes must now have been due to the severance of the influence of some other encephalic motor organ, whose previous unchecked activity was the cause, either indirectly or directly, of the rigidity and exaggerated reflexes. But what other organ of the kind is there-that is, what other motor organ-save the cerebellum? It was under the influence of such considerations, and after a careful comparison of the various hypotheses which have been started to explain these phenomena, that I came to the conclusion that a notion closely akin to that of Dr. Hughlings Jackson was most capable of explaining all the facts. Yet, as I have pointed out (loc. cit., p. 224), my reasons in detail, dependent upon views as to the precise modes of activity of the cerebellum, were rather different from those which he has set forth.

The doctrine that has hitherto found most favour has been that of Bouchard, Charcot, Brissaud, and others. It starts with certain positions which are common to both explanations of exaggerated teudon reactions and rigidity. These are (a) that exalted tendon reactions depend upon an exalted condition of "tone" in the muscles concerned; and (b) that the rigidities with which exalted tendon re- 
actions are often associated are only higher manifestations of similar phenomena, produced in an essentially similar manner.

It is here, however, that the two principal explanations that have been given of these phenomena part company. According to the view of the French school, which has been so widely adopted in this country, the phenomena are held to be immediate consequences of the degenerative changes set up in the "crossed pyramidal tracts" by injuries to these tracts higher up, either in the brain or in the spinal cord itself. The degenerative changes in the terminal portion of these fibres are supposed to cause an irritative over-action in the related great ganglion-cells of the anterior cornua, and thus to lead to an exaggerated condition of "tonus" in the muscles, and the production of the phenomena in question.

Great difficulties formerly stood in the way of explaining many of the facts without the aid of some such views (although grave objections could always be alleged against them); hence the few adherents which the counter explanation of Dr. Hughlings Jackson has hitherto been able to command. Now, however, it seems to me that the new facts established in this paper will be found to be altogether opposed to the fashionable views above cited, and to be just as much in favour of some modification of the doctrine of Hughlings Jackson.

One grave objection which always seemed to me much opposed to the view of Bouchard, Charcot, and others, was the fact that exalted tendon reactions and contracture are to be met with in many cases where there is every reason to believe that no such causative structural changes as the hypothesis assumes exist in the crossed pyramidal tracts, as, for instance, for a time after attacks of Jacksonian epilepsy ; ${ }^{1}$ again, in cases where mere temporary pressure is exerted upon the antero-lateral columns of the cord; and lastly, in many functional conditions, hysterical or

1 See Dr. Hughlings Jackson's paper, "On a Case of Temporary Left Hemiplegia," “Med. Times and Gaz.,' Feb. 12th, 1881.

VOL. LXXIII. 
other. Now, however, there appears a graver objection still; it is that in cases of total transverse lesions of the cord, as we have seen, the supposed cause exists to its fullest extent, viz. degeneration in the crossed pyramidal tracts, and yet, instead of exalted tendon reactions with rigidity, even after many weeks in some of the cases there is a total absence of reflexes, and a flaccid condition of the limbs. Here, then, as it seems to me, is the death-blow to the hitherto commonly accepted hypothesis.

Now let us look to the other mode of interpretation; let us see what can be said in favour of the view that "tonus" is in the main due to some encephalic influence exerted upon the spinal cord, seeing that the cutting this organ off from all encephalic influence leads to abolition of rigidity and of reflexes. This general position, as I have formerly urged, would seem to be pretty well established by my observations. Further, it seems highly probable that the potent encephalic influence which is thus cut off, in cases of total transverse lesions of the spinal cord, is that of the cerebellum. We cannot immediately, however, come to such a conclusion.

All that we are entitled to infer at once is that the severance of the cord from the brain greatly diminishes, at all events, what is known as "tonus,"-that is, diminishes it to such an extent that phenomena acknowledged to depend upon it can no longer be produced. Of this broad fact two explanations seem possible: thus it might be said (1) that owing to the mere fact of the complete severance of the lower half of the cord from the brain the nervous tension, so to speak, or degree of molecular activity in the grey matter of the severed portion of the cord, is so lowered as to lead to such a diminution of tonus. That is to say, that mere vague and diffused nerve impulses habitually passing between the brain and the spinal cord may be essential to the proper functional activity of the centres contained in the latter; that such impulses may maintain a condition of receptivity with correlative power of reaction, which in the absence of such conditions be- 
comes lost. This is a kind of explanation that might suffice to account for the negative phenomena, the mere loss of the reflexes and of rigidity, but it is powerless for the explanation of other related positive phenomena; that is to say, of and by itself it furnishes no explanation whatever of the fact that when the influence of the cerebral hemispheres alone is cut off we have the production of greatly exaggerated tendon reactions with more or less of rigidity or contracture.

It is, therefore, the insufficiency of the first mode of explanation that compels us to seek for another. Now, the other explanation, that which I have previously offered (loc. cit., p. 219), is this: We may suppose (2) " that the condition known as muscular tonus is mainly due to cerebellar influence acting upon and through the spinal centres; then it may well be that the removal of cerebral influence from certain parts of the spinal cord may allow cerebellar influence to reach such parts of the cord much more freely than natural-that is, as Hughlings Jackson would say, we should have to do with an unantagonised, or, as I would rather say, an unrestrained influx of cerebellar energy." Further evidence bearing upon the relative merits of this and of the other hypothesis was offered in the following remarks:- "The fact that such muscular irritability, in patients suffering from slight contracture, is increased if they take strychnia, has been commonly held to prove that this irritability is dependent upon changes or conditions existing within the spinal grey matter alone. But if we bear in mind that the muscular irritability in such cases is similarly exalted by mental activity or excitement, or by the performance of voluntary movements, and that it is often notably diminished by sleep, we may see in these facts reasons for

1 In addition to the facts already urged in support of such a view, I cited what had occurred in regard to reflexes in a remarkable case of complete thrombosis of the basilar artery, as well as in a case of ingravescent apoplexy. These f.cts, however, as I now recornise, are of doubtful cogency, because it cannot with certainty be said that the luss of the retlexes might not have been effects due to shock. 
believing that the excitability of the cord increases or diminishes with the excitement or the reverse of some encephalic centres, and that an excessive influence of some kind, producing increased tonus in the paralysed muscles, must reach the related ganglion-cells of the spinal cord through other channels than the damaged pyramidal tract."

Another question now presents itself. Supposing the cerebellum does exercise some such influence as $I$ have postulated upon the various centres in the spinal cord, it may naturally be asked, through what channels are we to imagine this influence to be conveyed? There would seem to be only two possible routes; that is, either through the " comma-shaped tracts," which is to my mind very unlikely, or else diffusely through the grey matter itself, in the same sort of way that impressions of pain are conveyed in the reverse direction.

Now, first of all in regard to the "comma-shaped tracts." I mention them because they are the only outgoing tracts at present known in the cord, the functions of which are sufficieutly uncertain to make it just possible that they are accustomed to convey cerebellar incitations to the muscles, and because the views of Dr. Hughlings Jackson are based in part upon the supposed existence of some definite outgoing cerebellar channels in the spinal cord. Thus he says ('Medical Examiner,' March 28th, 1878), "The hypothesis starts with the assumption that the spinal centres receive impulses from both the cerebrum and the cerebellum, which impulses in health interfere with one another (inhibit one another)." His meaning is made clearer by what follows : "In other words, loss of cerebral influence on the spinal centre may permit the rigidity, for then the cerebellar influence is no longer interfered with, and, metaphorically speaking, "flows into the parts deserted by the cerebral influence.' Hence it is better to say ' unantagonised cerebellar influx' than ' increased cerebellar influx.', For my own part, I cannot believe that the motor cells in the spinal cord are habitually the seat of antagonising activities emanating 
from the cerebrum and the cerebellum respectively; and the fact that the fibres of the "comma-shaped tracts" seem to terminate principally in the upper half of the spinal cord, and to disappear before the lumbar region is reached, is also opposed to the possibility that this as yet unallotted tract of outgoing fibres should have any such function. ${ }^{1}$

The only other channel, therefore, along which the slight molecular pulses could habitually pass from the cerebellum to the spinal cord (whose existence I postulate) is through the grey matter. These molecular pulses, whatever else they may do, may be supposed to be instrumental in maintaining the tonus of muscles throughout the body; while in various morbid states the amount of energy flowing along their habitual channels from the cerebellum (especially when the usual restraining influence of the cerebrum is withdrawn) may be very notably increased, so as to lead to rigidities and contractures. The notion that the grey matter is the channel along which these influences emanating from the cerebellum pass, I am not able to support by any more definite evidence than is to be found in the following facts.

We know that with absolute paralysis of the lower extremities, so long as sensibility is intact (as is so often the case in the paralysis associated with Pott's disease), the knee-jerks are greatly exaggerated, ankle-clonus is present, and there is more or less of rigidity with spasmodic twitchings. This condition of things existed also in the early stage of my Case 3. On the other hand, where there is more and more loss of sensibility, including loss of painful as well as of tactile impressions, the clinical picture changes: ${ }^{2}$ after a time we gradually lose the

1 Concerning the topography of the "comma-shaped tract," see Tooth, “On Secondary Degeneration of the Spinal Cord," 1889, p. 37.

2 What follows does not hold good for the effects of unilateral paralysis with anæsthesia. I have now, for instance, a young woman under my care in the National Hospital, in whom the right arm and leg are completely paralysed, all modes of sensibility being also lost; but the paralysed limbs are more or less rigid, and the knee-jerk is greatly exaggerated. 
rigidities, the spontaneous twitchings, and ankle-clonus; while with still graver impairments of sensibility the knee-jerks and the reflex movements of the limbs when the muscles are pricked may also disappear; or, fnally, these last may continue, together with some slight amount of plantar reflex, so long as even a slight amount of sensibility to painful impressions persists. ${ }^{1}$ This last condition was seen in my Case 2 on December 13th, and in Case 4 on March 17th. But we know that painful impressions are likewise conducted through the grey matter of the cord. Thus it would seem that the preservation of even the smallest bridge of grey matter may permit some preservation of painful impressions, and may at the same time permit the passage of cerebellar energy in the reverse direction. I have found, moreover, a remarkable case recorded by Dr. Thorburn, ${ }^{2}$ some details of which are subjoined, and which bears in a very interesting manner upon this question as to the channel by which the encephalic influence that serves to maintain tonus in the muscles is conducted.

10. J. B-, æt. 34, was admitted into hospital on December 30th, 1885. He was a carter, and whilst loading a waggon a "tippler" full of coal fell upon him, throwing him upon his face, while the coal struck him between the shoulders. On examination several hours after the accident there was absolute paralysis of both lower extremities, with deficient action of the intercostal and anterior abdominal muscles in respiration. Both legs were completely anæsthetic as high as the knees, but thence upwards he had some sensation, although there was distinct numbness as high as a line drawn round the abdomen about two inches below the umbilicus. The plantar reflexes were noted as "almost absent." "On the following day there was still absolute paralysis of the lower limbs, but there was now no anæsthesia. . . . The superficial reflexes and tendon reactions were everywhere absent. . . . The temperature was $98.6^{\circ} \mathrm{F}$. in the morning, and $99.8^{\circ} \mathrm{F}$. in the evening." On the follow-

1 In proof of these statements I would refer to what is stated as to Case 3 on p. 178, and in the notes for December $9 \mathrm{th}$; and $I$ would ask the reader to compare what is said on pp. 200 and 201 with the notes made as to Case 1 on May 19 th (p. 161) when seusibility was completely abolished.

2 'A Contribution to the Surgery of the Spinal Cord,' 1889, p. 48. 
ing day the signs of lung troubles with accumulation of mucus became severe, and the day after, January $2 \mathrm{nd}, 1886$, he died. At the autopsy the membranes of the cord were seen to be quite normal, as was the external appearance of the cord itself, but "on section there was found to be a dark black hamorrhage into the central gres matter in the lower cervical and upper dorsal recrions. This hemorrhage, which measured in its vertical extent from $1 \frac{1}{2}$ to 2 inches, was in the greater part of its extent situated centrally, occupying the whole of the central grey matter, and extending but little into the white substance, which in its neighbourhood was merely softened and of a faintly yellow tinge. At the lower part, for a very short distance, the hæmorrhage was limited to the anterior cornu of the right side, while the corresponding left horn appeared to be perfectly healthy. Elsewhere the cord was firm, and presented no abnormality."

Now this case seems to have for me almost all the value of a well-devised experiment. On the second day, when all the reflexes were still absent, though, as the notes say, "there was now no anæsthesia," all signs of shock seem to have disappeared. This continued absence of the reflexes with the return of sensibility seems to be distinctly opposed to the teaching of the cases that I have brought forward in this paper. In reality, however, I believe it to be the kind of seeming exception which tends to prove very fully the truth of many of the conclusions at which I have arrived. It tends to show almost conclusively that analgesia is the kind of defective sensibility which is most potential in bringing about a diminution or loss of the reflexes, and therefore the great importance of recording the state of a patient's sensibility to painful as well as to mere tactile impressions; for it can scarcely be doubted that in this case, where the autopsy showed a lesion limited to and invading the whole of the grey matter of the cord for a certain extent, there must have been, though it is not recorded, loss of sensibility to painful impressions. As we have seen, there was here certainly loss or very great diminution of "tonus" in the muscles, seeing that the "superficial reflexes and tendon reactions were everywhere absent."

I would only say a few words in conclusion as to the 
functional relations existing between the cerebrum and the cerebellum, and as to the conditions under which an excess of cerebellar influence becomes drafted into the spinal cord.

"In my opinion, the weakening or removal of cerebral influence from the spinal cord leads to the weakening or removal of an inhibitory influence which (operative probably in the pons Varolii) usually regulates or restrains the outflow of cerebellar energy through its median peduncles. I would not in the present state of knowledge attempt to define in what precise way the cerebrum and the cerebellum co-operate with one another in their possible actions upon the different muscles of the body. ${ }^{1}$ In the performance of the most automatic actions the cerebellum may come into play to a considerable extent independently of the cerebrum, and such neuro-muscular processes are comparatively little interfered with by unilateral lesions of the cerebrum. In the performance of the least automatic actions, however, the cerebrum takes the lead, and the cerebellum acts only as it is solicited or permitted to act, in directions indicated by the outgoing cerebral incitations. The withdrawal, owing to unilateral lesions, of cerebral influence from muscles which are principally called into action voluntarily is, therefore, well calculated greatly to interfere with ' the balance of power' usually capable of being brought to bear upon such muscles, and may lead, as it seems to do, to their being acted upon in excess by the cerebellum, even when in a state of rest, in consequence of which there is increased tonus, carrying with it exaltation of deep reflexes or even muscular rigidities.",2

Such effects do not usually manifest themselves to their fullest extent at once; they are immediately increased to some degree, but they go on increasing to an indefinite extent, so that it may be some days before anything like distinct rigidity shows itself. But, as I have said elsewhere," " it may be that in such cases the extra leakage

1 See ' The Brain as an Organ of Mind, pp. 503-510.

2 'Paralyses; Cerebral, Bulbar, and Spinal,' p. 222.

3 Loc. cit., p. $2 \pm 5$. 
of cerebellar energy, which the cerebral lesion permits after the shock occasioned by its occurrence has had time to resolve, has a tendency to go on increasing up to a certain point, because of the gradually lessening resistance (probably in the pons) opposed to any such overflows of cerebellar molecular energy. All nerve actions, whether normal or abnormal, become easier and recur all the more readily the more frequently they are repeated."

(For report of the discussion on this paper, see 'Proceedings of the Royal Medical and Chirurgical Society,' Third Series, vol. ii, p. 71.) 